\title{
Forecasting Volatility in European Stock Markets with Non-Linear GARCH Models
}

\author{
Gianfranco Forte and Matteo Manera
}

NOTA DI LAVORO 98.2002

\section{NOVEMBER 2002}

ETA - Economic Theory and Applications

\section{Gianfranco Forte, Institute of Financial Intermediaries, Bocconi University, Milan, Italy Matteo Manera, Institute of Economics, Bocconi University, Milan, Italy, Department of Statistics, University of Milan-Bicocca, Italy and Fondazione Eni Enrico Mattei, Milan, Italy}

This paper can be downloaded without charge at:

The Fondazione Eni Enrico Mattei Note di Lavoro Series Index: http://www.feem.it/web/activ/_wp.html

Social Science Research Network Electronic Paper Collection: http://papers.ssrn.com/abstract_id=XXXXXX

The opinions expressed in this paper do not necessarily reflect the position of 


\title{
Forecasting Volatility in European Stock Markets with Non-linear GARCH Models
}

\begin{abstract}
Summary
This paper investigates the forecasting performance of three popular variants of the nonlinear GARCH models, namely VS-GARCH, GJR-GARCH and Q-GARCH, with the symmetric GARCH $(1,1)$ model as a benchmark. The application involves ten European stock price indexes. Forecasts produced by each non-linear GARCH model and each index are evaluated using a common set of classical criteria, as well as forecast combination techniques with constant and non-constant weights. With respect to the standard GARCH specification, the non-linear models generally lead to better forecasts in terms of both smaller forecast errors and lower biases. In-sample forecast combination regressions are better than those from single Mincer-Zarnowitz regressions. The out-of-sample performance of combining forecasts is less satisfactory, irrespective of the type of weights adopted.
\end{abstract}

Keywords: Volatility, GARCH, forecast evaluation

JEL: A10, C10, C50, G10

The second author would like to thank the Graduate School of International Corporate Strategy at Hitotsubashi University, Tokyo, for its hospitality. A special thanks to Felix Chan, Umberto Cherubini, Toshiki Honda, Michael McAleer, Ryozo Miura, and Kazuhiko Oashi for their many insightful suggestions. Most computations have been based on modifications of the Gauss programs which complement the book by Franses and van Dijk (2000) and can be downloaded from the following URL: http://www.few.eur.nl/few/people/franses.

Address for correspondence:

Matteo Manera

Istituto di Economia Politica

Università Commerciale "L. Bocconi"

Via R. Sarfatti, 25

20136 Milano

Italy

Phone: +39-02-58365413

Fax: +39-02-58365439

E-mail: Matteo.Manera@uni-bocconi.it 


\section{Forecasting Volatility in European Stock Markets with Non-linear GARCH Models}

\section{Introduction}

Non-linear GARCH models (see Hentschel, 1995, for a survey) extend the seminal contributions by Engle (1982) and Bollerslev (1986) to incorporate the asymmetric impacts of shocks or news of equal magnitude but opposite sign on the conditional variance of asset returns. In this paper we investigate the forecasting performances of three popular variants of non-linear GARCH specifications, namely Volatility Switching (VS-GARCH), GJR-GARCH and Quadratic (Q-GARCH), using the symmetric $\operatorname{GARCH}(1,1)$ as a benchmark. The application involves ten European stock market indexes.

Following Poon and Granger (2001), it is possible to divide the current literature on forecasting volatility in financial markets in two main veins. The first one refers to models based on historical prices (time series, or TS, approach), whereas the second comprises those techniques which forecast volatility from actual option prices via the link with the BlackSholes's model (option implied standard deviation approach).

This paper belongs to the TS approach, which starts with the work by Taylor (1987) on forecasting the future volatility of the DM/\$ exchange rate series. Dimson e Marsh (1990) investigate the forecasting performance of some simple models applied to the U.K. stock market, such as Random Walk (RW), Historical Average, Moving Average, Exponential Smoothing and linear regressions. Akgiray (1989) is the first who uses the GARCH model to forecast volatility, showing that the $\operatorname{GARCH}(1,1)$ outperforms some of the techniques discussed in Taylor (1987). On the contrary, Cao and Tsay (1992) point out that the Threshold Autoregressive model produces better forecasts than GARCH, Exponential GARCH e ARMA models on the U.S.A. stock market. The forecasting behaviour of the Stochastic Volatility (SV) model is even more controversial. On the one hand, Heynen (1995) and Yu (2002) confirm the validity of the SV model when applied to stock market indexes, on the other hand 
Dunis, Laws and Chauvin (2001) document some difficulties for this model to forecast exchange rate volatility.

Tse and Tung (1992) strongly prefer the Exponentially Weighted Moving Average model to the GARCH(1,1) for the Singapore stock market. This is mainly attributable to the non-stationary variances of Singapore stock market indexes, while the standard GARCH model imposes stationarity. Brailsford and Faff (1996) select the GJR-GARCH(1,1) as the best model for the Australian stock index, although they point out that the final choice is not independent of the adopted evaluation criteria. On the same Australian stock index, Walsh and Tsou (1998) reject the GARCH model, whereas Brooks (1998) is not able to select the most appropriate model for the Dow Jones composite. Finally, Franses and Van Dijk (1996) compare RW, GARCH, Q-GARCH and GJR-GARCH specifications and show that QGARCH is the most successful in forecasting the volatility of stock price indexes for Italy, Spain, Germany and Sweden.

Such different and often contrasting results are mainly due to the lack of any common procedure to produce and evaluate competing sets of forecasts, especially in terms of number of time series subject to scrutiny, frequency of the data, forecasting horizons and loss functions.

With respect to the previous literature, this paper contains several distinguishing elements. First, a large number of European stock markets is analyzed. Second, samples and data frequencies are kept homogeneous throughout the empirical investigation. Third, forecasts produced by different models are compared using a common set of classical criteria and more recent forecast combination techniques with constant and non-constant weights.

The structure of the paper is as follows. Section 2 presents the main characteristics of the non-linear GARCH models used in the empirical analysis. Section 3 is dedicated to a discussion of the criteria adopted to compare different sets of forecasts. In Section 4 the data set is briefly described, and the forecasting performance of each non-linear GARCH model for each stock market index is analyzed. Section 5 contains some concluding comments. 


\section{Non-linear GARCH models: VS-GARCH, GJR-GARCH and Q-GARCH}

\subsection{The GJR-GARCH model}

This model has been introduced by Glosten, Jagannathan and Runkle (1993). It is based on a modification of the conditional variance equation of a $\operatorname{GARCH}(1,1)$, which assumes that the parameter of $\varepsilon_{t-1}^{2}$ depends on the sign of the shock:

$$
h_{t}=\alpha_{0}+\alpha_{1} \varepsilon_{t-1}^{2}\left(1-\mathrm{I}\left[\varepsilon_{t-1}>0\right]\right)+\gamma_{1} \varepsilon_{t-1}^{2} \mathrm{I}\left[\varepsilon_{t-1}>0\right]+\beta_{1} h_{t-1},
$$

where I[-] is an indicator function. The non-negativity conditions for the conditional variance are $\alpha_{0}>0,\left(\alpha_{1}+\gamma_{1}\right) / 2 \geq 0$ and $\beta_{1}>0$, whereas the process is covariance-stationary if $\left(\alpha_{1}+\gamma_{1}\right) / 2+\beta_{1}<1$. If this condition is satisfied, the unconditional variance is $\sigma^{2}=\alpha_{0} /\left(1-\left(\alpha_{1}+\gamma_{1}\right) / 2-\beta_{1}\right)$.

From equation (1) it is easy to notice that this model allows the coefficients of $\varepsilon_{t-1}^{2}$ to take different values corresponding to positive or negative shocks. Using equation (1), and assuming that the distribution of $\eta_{t}$ is symmetric around zero, it is possible to obtain the 2step ahead forecast for the conditional variance as:

$$
\hat{h}_{t+2 \mid t}=\mathrm{E}\left[\alpha_{0}+\alpha_{1} \varepsilon_{t+1}^{2}\left(1-\mathrm{I}\left[\varepsilon_{t+1}>0\right]\right)+\gamma_{1} \varepsilon_{t+1}^{2} \mathrm{I}\left[\varepsilon_{t+1}>0\right]+\beta_{1} h_{t+1} \mid \Omega_{t}\right]
$$

Equation (2) can be simplified by assuming that $\mathrm{E}\left[\mathrm{I}\left[\varepsilon_{t+1}>0\right]\right]=P\left(\varepsilon_{t+1}>0\right)=0.5$ and $\mathrm{E}\left[\varepsilon_{t+1}^{2} \mid \Omega_{t}\right]=h_{t+1}$, since $\varepsilon_{t+1}^{2}$ and the indicator function $\mathrm{I}\left[\varepsilon_{t+1}>0\right]$ are uncorrelated:

$$
\hat{h}_{t+2 \mid t}=\alpha_{0}+\left(\left(\alpha_{1}+\gamma_{1}\right) / 2+\beta_{1}\right) h_{t+1}
$$

s-step ahead forecasts can be computed recursively as 


$$
\hat{h}_{t+s \mid t}=\alpha_{0}+\left(\left(\alpha_{1}+\gamma_{1}\right) / 2+\beta_{1}\right) \hat{h}_{t+s-1 \mid t},
$$

or, without using previous forecasts:

$$
\hat{h}_{t+s \mid t}=\alpha_{0} \sum_{i=0}^{s-1}\left(\left(\alpha_{1}+\gamma_{1}\right) / 2+\beta_{1}\right)^{i}+\left(\left(\alpha_{1}+\gamma_{1}\right) / 2+\beta_{1}\right)^{s-1} h_{t+1} .
$$

\subsection{The VS-GARCH model}

This model has been proposed by Fornari and Mele $(1996,1997)$ as a generalization of the GJR-GARCH (1), where typically $\gamma_{1}<\alpha_{1}$, that is shocks of the same magnitude but opposite sign have a different impact on the next-period volatility.

The VS-GARCH model originates from the intuition in Rabemananjara and Zakoïan (1993), according to which the asymmetric behaviour of $h_{t}$ depends not only on the sign, but also on the dimension of the shock.

Fornari and Mele (1996) refer to an asymmetric behaviour of the volatility which is invertible as the dimension of the shocks varies. If shocks are small (large), positive (negative) shocks have higher impact on the volatility.

The equation for the conditional variance of a VS-GARCH $(1,1)$ is

$$
h_{t}=\left(\alpha_{0}+\alpha_{1} \varepsilon_{t-1}^{2}+\beta_{1} h_{t-1}\right)\left(1-\mathrm{I}\left[\varepsilon_{t-1}>0\right]\right)+\left(\phi_{0}+\phi_{1} \varepsilon_{t-1}^{2}+\gamma_{1} h_{t-1}\right) \mathrm{I}\left[\varepsilon_{t-1}>0\right] \text {. }
$$

The unconditional variance of this model is the same as in the $\operatorname{GARCH}(1,1)$, with the only difference that now the single coefficients are substituted with the arithmetic mean of the coefficients of the two regimes:

$\sigma^{2}=\left(\alpha_{0}+\phi_{0}\right) /\left[1-\left(\alpha_{1}+\phi_{1}\right) / 2-\left(\beta_{1}+\gamma_{1}\right) / 2\right]$. 
Fornari and Mele (1997) show that the kurtosis for this model is larger than that of a simple GARCH $(1,1)$ with parameters equal to the mean between the parameters in the two regimes of the VS-GARCH.

Using expression (3), we can calculate 2-step-ahead forecasts as:

$$
\begin{aligned}
\hat{h}_{t+2 \mid t}= & \mathrm{E}\left[\left(\alpha_{0}+\alpha_{1} \varepsilon_{t+1}^{2}+\beta_{1} h_{t+1} \mid \Omega_{t}\right)\left(1-\mathrm{I}\left[\varepsilon_{t+1}>0\right]\right)+\right. \\
& \left(\phi_{0}+\phi_{1} \varepsilon_{t+1}^{2}+\gamma_{1} h_{t+1} \mid \Omega_{t}\right) \mathrm{I}\left[\varepsilon_{t+1}>0\right] .
\end{aligned}
$$

Recalling that $\varepsilon_{t+1}^{2}$ and the indicator function $\mathrm{I}\left[\varepsilon_{t+1}>0\right]$ are uncorrelated, that $\mathrm{E}\left[\mathrm{I}\left[\varepsilon_{t+1}>0\right]\right]=P\left(\varepsilon_{t+1}>0\right)=0.5$ and that $\mathrm{E}\left[\varepsilon_{t+1}^{2} \mid \Omega_{t}\right]=h_{t+1}$, the following simplification applies:

$$
\hat{h}_{t+s \mid t}=\alpha_{0}+\left(\left(\alpha_{1}+\phi_{1}\right) / 2+\left(\beta_{1}+\gamma_{1}\right) / 2\right) \hat{h}_{t+s-1 \mid t}
$$

and the general recursive expression can be obtained:

$$
\hat{h}_{t+s \mid t}=\sum_{i=0}^{s-1} \alpha_{0}+\left(\left(\alpha_{1}+\phi_{1}\right) / 2+\left(\beta_{1}+\gamma_{1}\right) / 2\right)^{i}+\alpha_{0}+\left(\left(\alpha_{1}+\phi_{1}\right) / 2+\left(\beta_{1}+\gamma_{1}\right) / 2\right) h_{t+1}
$$

which allows us to calculate s-period-ahead forecasts based on the knowledge of $h_{t+1}$ only.

\subsection{The Q-GARCH model}

The Q-GARCH model is originally due to Sentana (1995). The equation for the conditional variance is

$$
h_{t}=\alpha_{0}+\gamma_{1} \varepsilon_{t-1}+\alpha_{1} \varepsilon_{t-1}^{2}+\beta_{1} h_{t-1}
$$


With respect to the simpler $\operatorname{GARCH}(1,1)$ model, only the term $\gamma_{1} \varepsilon_{t-1}$ is added, which allows for the asymmetric impact of positive and negative shocks. Equation (4) can be alternatively rewritten as

$$
h_{t}=\alpha_{0}+\left(\frac{\gamma_{1}}{\varepsilon_{t-1}}+\alpha_{1}\right) \varepsilon_{t-1}^{2}+\beta_{1} h_{t-1}
$$

If $\gamma_{1}$ is negative, the impact of negative shocks is larger than the impact of positive shocks. Moreover, the asymmetry of the impact varies as the dimension of the shock varies, in particular the asymmetric impact decreases as the dimension of the shock increases.

The autocorrelation function and the condition for weak stationarity are identical to the $\operatorname{GARCH}(1,1)$ model. Since the index of kurtosis for $\varepsilon_{t}$ is a positive function of the module of $\gamma_{1}$, the Q-GARCH model is able to rationalize excess kurtosis in asset returns.

The asymmetric term $\gamma_{1} \varepsilon_{t-1}$ in equation (4) has no effect on the forecast computation algorithm, since the expected value of $\varepsilon_{t+i}, i>0$, is zero by assumption. However, the presence of $\gamma_{1} \varepsilon_{t-1}$ affects the forecast error:

$$
\begin{aligned}
v_{t+s \mid t} & \equiv h_{t+s}-\hat{h}_{t+s \mid t} \\
& =\gamma_{1} \varepsilon_{t+s-1}+\alpha_{1}\left(\varepsilon_{t+s-1}^{2}-\hat{\varepsilon}_{t+s-1 \mid t}^{2}\right)+\beta_{1}\left(h_{t+s-1}-\hat{h}_{t+s-1 \mid t}\right) \\
& =\gamma_{1} \varepsilon_{t+s-1}+\alpha_{1} v_{t+s-1}+\left(\alpha_{1}+\beta_{1}\right) v_{t+s-1 \mid t} \\
& =\alpha_{1} \sum_{i=1}^{s-1}\left(\alpha_{1}+\beta_{1}\right)^{i-1} v_{t+s-i}+\gamma_{1} \sum_{i=1}^{s-1}\left(\alpha_{1}+\beta_{1}\right)^{i-1} \varepsilon_{t+s-i} .
\end{aligned}
$$

Forecasts are still unbiased, since, given that $\mathrm{E}\left[v_{t+s-i} \mid \Omega_{t}\right]=\mathrm{E}\left[\varepsilon_{t+s-i} \mid \Omega_{t}\right]=0$ for any $i=1, \ldots, s-1, \mathrm{E}\left[v_{t+s \mid t} \mid \Omega_{t}\right]=0$. Nevertheless, the conditional variance of $v_{t+s \mid t}$ is larger than the corresponding conditional variance of the $\operatorname{GARCH}(1,1)$ model, which in turn means that uncertainty associated to the forecast of $h_{t+s}$ is now larger. 


\section{Forecasting evaluation methods for non-linear GARCH models}

\subsection{Classical evaluation criteria}

Define the loss differential as

$$
d_{j}=e_{n+\lambda n+j-1, a}^{k}-e_{n+\lambda n+j-1, b}^{k} \quad \mathrm{j}=1,2, \ldots, \mathrm{m},
$$

where $e_{n+j n+j-1, a}^{k}$ and $e_{n+j n+j-1, b}^{k}$ are the forecast errors at time $n+j$ computed using models $a$ and $b$ respectively, and $k$ is equal to 2 (or 1 ) if the mean squared errors (or the mean absolute errors) are confronted.

Following Diebold and Mariano (1995), we concentrate our investigation on three tests. The first one is the so-called sign test ( $\mathrm{S}$ test), whose asymptotic version is given by:

$$
S=\frac{2}{\sqrt{m}} \sum_{j=1}^{m}\left(I\left[d_{j}>0\right]-\frac{1}{2}\right) \sim N(0,1)
$$

The underlying intuition of this statistic is simple. Assuming that the loss differential is IID, the number of positive observations in a sample of size $m$ has a binomial distribution with parameters $m$ and $1 / 2$. It is important to notice that the null hypothesis of this test is "median of the loss differential equal to zero", which coincides with the null of zero loss differential mean only if the distribution of the loss differential is symmetric (this is not always the case for the series we are about to analyze). Unfortunately, the S test does not take into consideration the magnitude of the spreads between the forecast errors of the two competing models.

The second statistic is the Diebold-Mariano test (DM test), which compares the module of the size of the forecast errors by testing whether the mean of the loss differential is significantly different from zero. In fact, it is possible to show that, if $d_{j}$ is a covariance stationary time series, the asymptotic distribution of its sample mean is

$$
\sqrt{m}(\bar{d}-\mu) \sim N(0, f)
$$


where

$$
\bar{d}=\frac{1}{m} \sum_{j=1}^{m}\left[\mathrm{~L}\left(e_{n+j \mid n+j-1, a}\right)-\mathrm{L}\left(e_{n+j \mid n+j-1, b}\right)\right],
$$

is the sample mean of the loss differential based on any loss function $\mathrm{L}[\cdot], f$ indicates the variance of the sample mean, whereas $\mu$ is the population mean of the loss differential. Thus, in large samples, under the null hypothesis of zero population mean of the loss differential, $\bar{d}$ has a standard normal distribution

$$
D M=\frac{\bar{d}}{\sqrt{\hat{f}}} \sim N(0,1),
$$

with $\hat{f}$ being a consistent estimator of the asymptotic variance of $\bar{d}$. Diebold and Mariano suggest to estimate $f$ using the non-weighted sum of the autocovariances for $d_{j}$

$$
\hat{f}=\frac{1}{m} \sum_{i=-(h-1)}^{h-1} \hat{\gamma}_{i}(d)
$$

$h$ being the forecasting horizon where the forecast errors are confronted.

Such an estimate of the asymptotic variance is motivated by the structure of the h-stepahead forecast error, which is a linear combination of the shocks occurred up to $h-1$ and thus is serially correlated up to order $h-1$. Obviously, for $h=1, \hat{f}$ is $\hat{\gamma}_{0}(d)$, that is the variance of $d_{j}$.

Alternatively, the DM test is a t-test of zero population mean of the loss differential, which considers that the loss differential is not necessarily a white noise process. As far as the choice of the loss function is concerned, it is important to notice that for most of the series under scrutiny the forecast errors and the loss differential are characterized by aberrant observations (larger, in absolute value, than three standard deviations), as well as by ARCH 
effects. Consequently, specifying L[.] with the absolute value function seems to be more appropriate, given that the traditional quadratic loss function would imply very large standard deviations and force the statistics to be in the non-rejection region most of the times.

A simple Lagrange Multiplier test reveals the presence of first-order ARCH effects in the loss differentials with L[.] specified with the absolute value function ${ }^{1}$. This result justifies the introduction of the Newey-West test (NW test), which is again a t-type statistic of the null hypothesis of zero mean loss differential. The difference with the DM test is given by the variance-covariance matrix, which in this case is estimated according to Newey and West (1987) and thus it is robust to autocorrelation and ARCH effects.

In many empirical studies (see, among others, Alkgiray, 1989; Brailsford and Faff, 1996) more traditional criteria are used to evaluate the forecasting performance of alternative non-linear GARCH models. Among the most commonly adopted measures are the mean squared (MSPE), the mean absolute (MAPE) prediction error, and, given the presence of aberrant observations and outliers in stock market returns, the median squared (MedSPE) and the median absolute (MedAPE) prediction error. For instance, when volatility is the object of the prediction exercise, MSPE is defined as

$$
\text { MSPE }=\frac{1}{m} \sum_{j=0}^{m-1}\left(\hat{h}_{n+s+j \mid n+j}-h_{n+s+j}\right)^{2} .
$$

A popular approach to evaluate the unbiasedness of the forecast $\hat{h}_{n+s+j \mid n+j}$ is the regression originally proposed by Mincer and Zarnowitz (1969) and further discussed in Fair and Shiller $(1989,1990)^{2}$ :

$$
h_{n+s+j}=a+b \hat{h}_{n+s+j \mid n+j}+e_{n+s+j}, \quad j=0, \ldots ., m-1,
$$

\footnotetext{
${ }^{1}$ Results from the Lagrange Multiplier ARCH test are not reported here to economize space.

${ }^{2}$ See also Pagan and Schwert (1990), Day and Lewis (1992), Lamoureux and Lastrapes (1993). It is advisable to use the Newey-West method to calculate the regression standard errors, since the error terms are generally serially correlated and heteroskedastic.
} 
where $a=0, b=1$ indicate, together with $\mathrm{E}\left(\hat{e}_{n+s+j}\right)=0$, unbiased forecasts.

The main obstacle to the practical use of these criteria is that the realized volatility $h_{n+s+j}$ in (7) and (8) is unobserved. One solution is to substitute $h_{t}$ with the squared shocks $\varepsilon_{n+s+j}^{2}=\eta_{n+s+j}^{2} h_{n+s+j}$. Since $\mathrm{E}\left[\eta_{n+s+j}^{2}\right]=1, \varepsilon_{n+s+j}^{2}$ is an unbiased estimate of $h_{n+s+j}$.

It is worth noticing that most empirical studies find that volatility forecasts based on linear and non-linear GARCH models are quite unsatisfactory, with very large MSPE and very low $R^{2}$ from regression (8). Moreover, the forecast unbiasedness hypothesis of $a=0$ in equation (8) is generally rejected (e.g. Andersen and Bollerslev, 1998, Christodoulakis and Satchell, 1998).

\subsection{Forecast combination}

The aim of the statistical criteria presented in Section 3.1 is to determine, among different competing models, the most accurate forecast relative to a pre-specified loss function. In many practical situations this is not an easy task, since each model is able to capture only a limited amount of information contained in the series of interest. If this is the case, an alternative and more appealing strategy is forecast combination or forecast encompassing (see Diebold and Lopez, 1996 for an exhaustive survey).

A forecast encompassing test allows us to verify whether a single forecast incorporates all the information included in the forecasts generated by alternative competing models. The intuition behind this approach is due to Nelson (1972) and Cooper and Nelson (1975), whereas its formalization appears in Chong and Hendry (1986).

Two forecasts are confronted, $y_{t+h \mid t}^{a}$ and $y_{t+h \mid t}^{b}$, which have been obtained by two different models $a$ and $b$. The forecast encompassing test is based on the following regression:

$$
y_{t+h}=\beta_{a} y_{t+h \mid t}^{a}+\beta_{b} y_{t+h \mid t}^{b}+\varepsilon_{t+h \mid t} .
$$

If $\left(\beta_{a}, \beta_{b}\right)=(0,1)$ or $\left(\beta_{a}, \beta_{b}\right)=(1,0)$, then model $b$ encompasses model $a$ (and viceversa). If this is not true, both forecasts include useful information on $y_{t+h}$. Standard 
hypothesis tests can be used, provided the time series involved in regression (9) are covariance-stationary and, for $h>1$, serial correlation of the error term $\varepsilon_{t+h \mid t}$ is taken into consideration.

A similar approach is proposed by Fair and Shiller $(1989,1990)$, which is based on the regression

$$
y_{t+h}-y_{t}=\beta_{a}\left(y_{t+h \mid t}^{a}-y_{t}\right)+\beta_{b}\left(y_{t+h \mid t}^{b}-y_{t}\right)+\varepsilon_{t+h \mid t}
$$

and accommodates the case of non-stationary, integrated forecasts using differences. The encompassing hypotheses can be tested in the present framework by invoking asymptotic normality of standard statistics. If the encompassing test rejects the null hypothesis, this evidence should be interpreted in favour of forecast combination. Even if the forecasts obtained by different models have white noise errors, this is not necessarily the case for the forecast combination. It is then important to allow for an error with an adequate $\operatorname{ARMA}(p, q)$ structure, when estimating the weights for the forecast combination. Moreover, additional information can be obtained if part of the forecasts is reserved to evaluate the empirical performance of the forecast combination.

\section{Empirical results}

The empirical application involves ten European stock price indexes, namely U.K., France, Germany, and Italy, followed by Belgium, Switzerland, Greece, Portugal, Spain and Holland. Table 1 reports sample sizes and frequencies for each series.

Table 2 presents some descriptive statistics on weekly and daily percentage returns $\left(y_{t}\right)$ of each stock price index $\left(p_{t}\right)$, defined as $y_{t}=100 *\left[\ln \left(p_{t}\right)-\ln \left(p_{t-1}\right)\right]$. From a simple inspection of this table, some key features which are typical of most financial time series are confirmed for these data. In particular, kurtosis is always larger than 3, especially for daily returns, whereas skewness is generally negative. 
The non-linear GARCH models discussed in Section 2 are now estimated to rationalize the stylized facts of Table 2. Their empirical performance is then compared with the standard linear $\operatorname{GARCH}(1,1)$ specification taken as the benchmark model.

\subsection{Results from classical evaluation criteria}

The following approach has been adopted to obtain alternative forecasts of conditional volatility. Each non-linear GARCH model has been estimated on a rolling window, whose size is constant within each stock index but varies across different indexes according to Table 3. Each window of constant size rolls over the sample step by step. At each step, a new window is formed by deleting the first observation and adding one observation to the last observation of the previous window. For each window, each series and each model, h-stepahead forecasts are obtained, $h=1, \ldots, 5$. Since the first five indexes presented in Table 1 are observed on a common sample, we use a 7-year rolling window, from the first week of 1987 to the last week of 1993. Consequently, in the first step volatility forecasts for the first 5 weeks of 1994 are obtained, in the second step volatility forecasts from week two to week seven of 1994 are generated, and so on until the last week of 2000. The result is given by five series of h-step-ahead forecasts, $h=1, \ldots, 5$, each series formed by 365 observations (number of weeks from the beginning of 1994 to the end of 2000). These series of forecasts are then summarized by computing the classical evaluation criteria described in Section 3.

Table 4 reports detailed results about the forecast accuracy analysis based on classical evaluation criteria. Each section of the table refers to a specific stock index, whereas the whole set of evaluation criteria is applied to each non-linear GARCH model — whose specification is always of order $(1,1)$ for the conditional variance and equal to the simple constant term for the mean equation - and calculated for each of the five forecasting horizons. Each section is composed by six columns, which indicate the selected evaluation criteria. In order to facilitate the comparison between each non-linear specification and the benchmark $\operatorname{GARCH}(1,1)$ model, the reported values of MSPE, MedSPE, MAPE, and MedAPE are equal to the calculated values divided by the corrisponding values obtained 
using the GARCH $(1,1)$ model $^{3}$. Columns five, six and seven in the table show the p-values for tests S, DM and NW. Once again, each non-linear GARCH model is confronted with the standard $\operatorname{GARCH}(1,1)$ on the same forecasting horizon.

For the DM test we have preferred the absolute value loss function to the popular quadratic specification, since the latter amplifies the largest values of the loss differential (sometimes up to thirty times). In this way, the standard deviation of the loss differential could be up to twenty times larger than the one obtained using the absolute value loss function. The DM test, which is in essence a t-test of the null hypothesis of zero constant robust to residual autocorrelation, is affected by this phenomenon and gives rise to small calculated values and large p-values. In addition, we have used the $\mathrm{S}$ test since it is based on the median, instead of the mean, of the loss differential. This is useful when, as in our context, the values of the loss differentials are characterized by extreme observations, which affect the mean, but not the median, of the distribution. Since the loss differentials are often asymmetric, the DM and S tests lead to conclusions about the null hypothesis which are often conflicting.

Since the loss differentials which are at the heart of the statistics reported in Table 4 show, for all models and forecast horizons, several extreme observations, the NW test has been recalculated using the series of the loss differentials once all the outliers have been removed. We define as an outlier in the series of the loss differential any observation that is larger than the triple of the loss differential standard deviation, that is when $\left|d_{j}\right|>r \sigma$, with $r=3$. The choice of $r=3$ has demonstrated to be appropriate for all series of the loss differential. P-values of the recalculated NW test are reported in Table 5.

From Tables 4 and 5 some interesting comments emerge. First, forecasting with GJR$\operatorname{GARCH}(1,1)$ and QGARCH$(1,1)$ does not yield a significant reduction of the forecast error relative to the $\operatorname{GARCH}(1,1)$, since in general the calculated values for MSPE, MedSPE, MAPE and MedAPE are close to one. Second, these results are confirmed if we take into consideration the modified version of the NW test reported in Table 5 (with the only exception of Greece when the GJR-GARCH model is used, Portugal and Belgium with respect to QGARCH). Third, the VS-GARCH(1,1) is the model whose forecasting

\footnotetext{
${ }^{3}$ Thus, for example, the first column of each section reports the percentage value of the MSPE criterion for each non-linear model and forecasting horizon with respect to the MSPE of the $\operatorname{GARCH}(1,1)$ for the same forecasting horizon.
} 
performance is less close to the $\operatorname{GARCH}(1,1)$, since the values taken by the four measures of forecast error are generally very far from unity. Four, if we concentrate on the VS$\operatorname{GARCH}(1,1)$, the measures of forecast error with values significantly less than unity are based, in all cases, on the median of the forecast error, since the forecasts produced by the VS-GARCH $(1,1)$ are more volatile than those of the remaining non-linear models. Finally, the tests of forecast accuracy confirm that the VS-GARCH(1,1) is the model which is more distant from the linear GARCH. In particular, the null hypothesis of equality of the forecasting accuracy between VS-GARCH$(1,1)$ and $\operatorname{GARCH}(1,1)$ is rejected in $70 \%$ of the cases. For at least six of the analyzed stock indexes (Holland, Belgium, France, Italy, Switzerland and Spain) the VS-GARCH model outperforms the linear GARCH, as well as the remaining non-linear models.

In Tables $6 \mathrm{a}-6 \mathrm{c}$ the main results from the Mincer-Zarnowitz regression (8) are reported. First, the $R^{2}$ values are low, typically less than 0.1 . Second, the forecasts obtained with the simple GARCH model are often biased. Third, the forecasting performance of GJR-GARCH and QGARCH is better than GARCH's. A possible explanation is that modelling asymmetries contributes to the reduction of the magnitude of the bias. Fourth, the more flexible VSGARCH generates forecasts with small bias, with the exception of U.K., Italy and Greece, where biases measured both in terms of slope and intercept are significant. Finally, in some cases (namely Italy and Greece) none of the analyzed models is able to produce forecasts with a $R^{2}$ in the Mincer-Zarnowitz regression larger than 0.03 .

Overall, the forecasting performance of each single model is unsatisfactory. For this reason it is interesting to investigate the potential complementarieties among alternative individual models using the forecast combination approach.

\subsection{Results from forecast combination}

The most popular technique of forecast combination is a regression involving the whole set of competing forecasts with associated time-invarying coefficients (weights) and a constant term, as described in Granger and Ramanathan (1984). The assumption of constant weights is obviously restrictive. As a matter of fact, the series we would like to forecast are 
the shocks $\varepsilon_{n+s+j}^{2}=\eta_{n+s+j}^{2} h_{n+s+j}$, which are unbiased estimators of $h_{n+s+j}$, and widely vary in time according to the evolution of volatility.

If constant weights are assumed in the linear combination, it is not possible to take into account the actual and highly volatile behaviour of the series of interest, as well as the temporal changes in the accuracy of the forecasts to combine. Thus, we have also proposed a forecast combination technique with variable weights.

In order to implement the forecast combination with constant coefficients, we have divided the sample of forecasts obtained by each of the four competing models in two parts. The first subsample is dedicated to the estimation of the weights of the linear combination, whereas the second is used to verify whether the set of weights obtained in the first part can replicate the linear combination out of sample. ${ }^{4}$ More specifically, we used $70 \%$ of the forecast sample to estimate the weights and the remaining $30 \%$ to evaluate the performance of the forecast combination out of sample. We omit to present the results of the encompassing forecast test into detail, since it always rejects the irrelevance of any of the selected models in the forecast combination.

Table 7 presents the estimated weights of the linear combination of forecasts for each stock index and forecasting horizon. It is informative to compare the $R^{2}$ from the forecast combination regressions of Table 7 with those from the Mincer-Zarnowitz regressions presented in Tables $6 \mathrm{a}-6 \mathrm{c}$ for each single model. The forecast combination leads to a generalized increase of the $R^{2}$, thus suggesting that different models include complementary information which can be used to better approximate actual volatility.

Tables $8 \mathrm{a}-8 \mathrm{~b}$ refer to the out-of-sample forecast performance of the forecast combination technique. The tables report both the forecast evaluation criteria applied to each single model and the results from the Mincer-Zarnowitz regression. Unfortunately, the good in-sample performance of the forecast combination technique is not always replicated out of sample.

\footnotetext{
${ }^{4}$ Forecast sample sizes are different for each selected index and coincide with the rolling windows indicated in Table
} 4. 
Despite the values taken by MSPE, MedSPE, MAPE and MedAPE are less than unity in several cases (i.e. the non-linear models outperform the simple $\operatorname{GARCH}(1,1)$ ), and the tests for forecast accuracy reject the null hypothesis, the $R^{2}$ of the Mincer-Zarnowitz regressions are always less than the $R^{2}$ relative to the in-sample combinations, and the $R^{2}$ obtained from each single model. A reasonable explanation is that the large volatility characterizing the series of the squared shocks does not allow to generalize to the second subsample the weights which have been estimated on the first subsample.

A simple way to take into account time in the forecast combination regression is to include a linear trend and/or interactions of the existing regressors (forecasts) with a linear trend. Such a way of dealing with time could be reasonable if the weights are trend varying, which is not our case. Figure 1 shows the temporal evolution of the five combination coefficients (constant included) relative to the 5-step-ahead forecasts for Italy. Specifically, $\mathrm{C}(1)$ is the coefficient of the GARCH forecast, $\mathrm{C}(2)$ is relative to GJR-GARCH, C(3) is the QGARCH coefficient and C(4) is the coefficient associated to VS-GARCH. All coefficients have been estimated using Recursive Least Squares. It is easy to see that each coefficient shows ample oscillations of both signs, which are hardly compatible with a linear trend.

In order to incorporate variable weights, a preferable approach is to estimate the parameters of the forecast combination within a rolling window of a fixed sample size, and use those estimates to combine the forecasts of each single model starting from the last observation included in the rolling window. The sample size of the combined forecasts is equal to the difference between the sample size of the individual forecasts and the number of observations defining the rolling window. The number of observations of the rolling window is not the same for each stock index: among several alternatives (namely 15, 20, 25, 30, 35 and 40 observations), the one with the highest $R^{2}$ in the Mincer-Zarnowitz regression has been selected.

Table 9 reports the sample size of each rolling window, whereas Tables 10a-10b show the results of the forecast combination technique with variable coefficients. The values taken by the forecast error measures and the accuracy evaluation tests suggest that out-of-sample forecast combination outperforms only partially the regression method. Actually, the $R^{2}$ of the Mincer-Zarnowitz regression is not always larger than the corresponding $R^{2}$ of the regression approach, while better results are obtained in terms of reduction of the forecast 
bias. When evaluated out of sample, the empirical performance of the regression method with constant or variable coefficients is not superior to the forecast results produced by individual linear and non-linear GARCH models.

\section{Conclusions}

The comparison between the forecasting accuracy of GARCH, GJR-GARCH, QGARCH and VS-GARCH does not indicate a dominant model. With respect to the standard GARCH specification which ignores potential asymmetries in asset returns, the non-linear models generally lead to better forecasts in terms of both smaller forecast errors and lower biases. The model which is empirically less close to the simple linear GARCH is the VSGARCH.

However, the volatility forecasts which have been generated using the four non-linear models are unsatisfactory, especially when evaluated on the basis of the $R^{2}$ associated to the Mincer-Zarnowitz regression, which is low in most of the cases.

Individual models take into account only a part of the actual behaviour of the series, tending to play a complementary role in explaining observed volatility. This is confirmed by the forecast combination regression applied to the sample where the combination weights are estimated, which produces significantly higher $R^{2}$ than those obtained from the individual Mincer-Zarnowitz regressions. When evaluated out of sample, the performance of the regression method is less satisfactory. Finally, the alternative technique of combining different forecasts with variable weights does not seem to represent a fully convincing solution. 


\section{References}

Alkgiray, V. (1989), "Conditional heteroschedasticity in time series of stock returns: evidence and forecasts", Journal of Business, 62, 55-80.

Andersen, T. and T. Bollerslev (1998), "Answering the skeptics: yes, standard volatility models do provide accurate forecasts”, International Economic Review, 39, 885-906.

Bollerslev, T. (1986), “Generalized autoregressive conditional heteroschedasticity”, Journal of Econometrics, 31, 307-327.

Brailsford T.J. and R.W. Faff (1996), “An evaluation of volatility forecasting techniques”, Journal of Banking and Finance, 20, 419-438.

Brooks, C. (1998), “Predicting stock market volatility: Can market volume help?”, Journal of Forecasting, 17, 1, 59-80.

Cao, C.Q. and R.S. Tsay (1992), "Nonlinear time-series analysis of stock volatilities", Journal of Applied Econometrics, December, Supplement, 1S, 165-185.

Chong, Y.Y. and D.F. Hendry (1986), "Econometric evaluation of linear macroeconomic models", Review of Economic Studies, 53, 671-690.

Cooper, D.M. and C.R. Nelson (1975), "The ex ante prediction performance of the St. Louis and of the F.R.B.-M.I.T.-Penn econometric models and some results on composite predictors", Journal of Money, Credit and Banking, 7, 1-32.

Christodoulakis, G.A. and S.E. Satchell (1998), "Hashing GARCH: a re-assessment of volatility forecasting performance", in Forecasting Volatility in the Financial Market, ed. by J. Knight and S.E. Satchell, New York, Butterworth-Heinemann.

Day, T.E. and C.M. Lewis (1992), "Stock market volatility and the information content of stock index options", Journal of Econometrics, 52, 267-287.

Diebold, F.X. and R.S. Mariano (1995), "Comparing predictive accuracy", Journal of Business and Economic Statistics, 13, 253-63.

Diebold, F.X. and J. A. Lopez (1996), "Forecast Evaluation and Combination", technical working paper $\mathrm{n}^{\circ}$ 192, National Bureau of Economic Reserch, Cambridge, Massachusetts.

Dimson, E. and P. Marsh (1990), "Volatility forecasting without data-snooping", Journal of Banking and Finance, 14, 399-421. 
Dunis, C.L., J. Laws and S. Chauvin (2001), "The use of market data and model combination to improve forecast accuracy" in Developments in Forecast Combination and Portfolio Choice, ed. by C. Dunis, J. Moody and A. Timmermann, Chichester, Wiley.

Engle, R.F. (1982), “Autoregressive conditional heteroschedasticity with estimates of the variance of United Kingdom inflation”, Econometrica, 50, 987-1007.

Fair, R.C. and R.J. Shiller (1989), “The infomational content of ex ante forecasts”, Rewiew of Economics and Statistics, 71, 325-332.

Fair, R.C. and R.J. Shiller (1990), "Comparing information in forecasts from econometric models", American Economic Rewiew, 80, 375-389.

Fornari, F. and A. Mele (1996), "Modelling the changing asymmetry of conditional variances”, Economics Letters, 50, 197-203.

Fornari, F. and A. Mele (1997), "Sign-and volatility-switching ARCH models: theory and applications to international stock markets", Journal of Applied Econometrics, 12, 4965 .

Franses, P.H. and D. Van Dijk (1996), "Forecasting stock market volatility using (non-linear) Garch models", Journal of Forecasting, 15, 3, 229-235.

Franses, P.H. and D. Van Dijk (2000), Non-Linear Time Series Models in Empirical Finance, Cambridge, U.K., Cambridge University Press.

Glosten, L.R., R. Jagannathan and D.E. Runkle (1993), "On the relation between the expected value and the volatility of the nominal excess return on stocks", Journal of Finance, 48, $1779-801$.

Granger, C.W.J. and R. Ramanathan (1984), “Improved Methods of Combining Forecasts”, Journal of Forecasting, 3, 197-204.

Hentschel, L.F. (1995), “All in the family: nesting linear and nonlinear GARCH models", Journal of Financial Economics, 39, 139-164.

Heynen, R.C. (1995), Essays on Derivatives Pricing Theory, Thesis Publishers, Amersterdam.

Lamoureux, C.G. and W.D. Lastrapes (1993), "Forecasting stock return variances: towards understanding stochastic implied volatility", Review of Financial Studies, 6, 293-326.

Mincer, J. and V. Zarnowitz (1969), "The Evaluation of Economic Forecasts”, in Economic Forecasts and Expectation, ed. by J. Mincer, National Bureau of Economic Reserch. 
Nelson, C.R. (1972), "The prediction performance of the F.R.B.-M.I.T.-Penn model of the U.S. economy", American Economic Review, 62, 902-907.

Newey, W.A. and K. West (1987), “A simple, positive semi-definite, heteroskedasticity and autocorrelation consistent covariance matrix", Econometrica, 55, 703-708.

Pagan, A.R. and G.W. Schwert (1990), “Alternative models for conditional stock volatility”, Journal of Econometrics, 45, 267-290.

Poon, S.H. and C.W.J. Granger (2001), "Forecasting financial market volatility: a review", manuscript, Department of Economics, University of California at San Diego.

Rabemananjara, M. and J.M. Zakoïan (1993), “Threshold ARCH models and asymmetries in volatility", Journal of Applied Econometrics, 19, 351-372.

Sentana, E. (1995), “Quadratic ARCH models”, Review of Economic Studies, 62, 639-61.

Taylor S.J. (1987), "Forecasting of the volatility of currency exchange rates", International Journal of Forecasting, 3, 159-170.

Tse, T.Y.K. and S.H. Tung (1992), "Forecasting volatility in the Singapore stock market", Asia Pacific Journal of Management, 9, 1-13.

Walsh, D.M. and G.Y-G Tsou (1998), "Forecasting index volatility: sampling integral and non-trading effects", Applied Financial Economics, 8, 477-485.

$\mathrm{Yu}$, J. (2002), "Forecasting volatility in the New Zealand stock market", Applied Financial Economics, 12, 193-202. 
Table 1. Sample size and frequency for ten European stock price indexes

\begin{tabular}{llc}
\hline \hline \multicolumn{1}{c}{ Stock markets } & Frequency (\# Observ.) & Sample \\
\hline Holland - Amsterdam AEX (EOE) & Daily (3788), weekly (757) & $(07 / 01 / 1987-13 / 07 / 2001)$ \\
Belgium - BBL 30 & Daily (3788), weekly (757) & $(07 / 01 / 1987-13 / 07 / 2001)$ \\
Germany - Dax 30 Performance & Daily (3788), weekly (757) & $(07 / 01 / 1987-13 / 07 / 2001)$ \\
U.K. - London FTSE 100 & Daily (3788), weekly (757) & $(07 / 01 / 1987-13 / 07 / 2001)$ \\
Italy - Milan Mib Storico & Daily (3788), weekly (757) & $(07 / 01 / 1987-13 / 07 / 2001)$ \\
France - CAC 40 & Daily (3653), weekly (730) & $(09 / 07 / 1987-13 / 07 / 2001)$ \\
Spain - Madrid SE General & Daily (3528), weekly (705) & $(01 / 05 / 1988-13 / 07 / 2001)$ \\
Portugal - PSI General & Daily (3528), weekly (705) & $(01 / 05 / 1988-13 / 07 / 2001)$ \\
Switzerland - Swiss Market & Daily (3398), weekly (679) & $(01 / 07 / 1988-13 / 07 / 2001)$ \\
Greece - Athens SE General & Daily (3333), weekly (666) & $(30 / 09 / 1988-13 / 07 / 2001)$ \\
\hline \hline
\end{tabular}

Notes to the table: the second column refers to the frequency of the data as well as the number of observations used in the empirical analysis

Table 2. Descriptive statistics on daily and weekly returns

\begin{tabular}{lccccccc}
\hline \multicolumn{1}{c}{ Stock markets } & Mean & Med & Min & Max & Var & Skew & Kurt \\
\hline Daily returns & & & & & & & \\
Holland & 0.042 & 0.040 & -12.779 & 11.182 & 1.439 & -0.589 & 14.872 \\
Belgium & 0.029 & 0.000 & -12.531 & 8.943 & 0.900 & -0.514 & 22.749 \\
Italy & 0.021 & 0.000 & -8.476 & 6.216 & 1.487 & -0.493 & 6.565 \\
U.K. & 0.031 & 0.019 & -13.029 & 7.597 & 1.001 & -1.058 & 17.847 \\
Germany & 0.038 & 0.037 & -13.710 & 7.288 & 1.723 & -0.760 & 11.453 \\
France & 0.033 & 0.000 & -10.138 & 8.225 & 1.579 & -0.415 & 8.187 \\
Portugal & 0.020 & 0.000 & -10.814 & 7.572 & 0.850 & -0.639 & 18.656 \\
Spain & 0.035 & 0.000 & -8.611 & 6.362 & 1.228 & -0.415 & 8.303 \\
Switzerland & 0.045 & 0.039 & -11.112 & 7.462 & 1.133 & -0.734 & 12.073 \\
Greece & 0.063 & 0.000 & -10.646 & 13.749 & 3.375 & 0.131 & 8.066 \\
\hline Weekly returns & & & & & & & \\
Holland & 0.208 & 0.418 & -17.362 & 11.278 & 5.953 & -0.991 & 8.584 \\
Belgium & 0.146 & 0.205 & -16.719 & 10.268 & 4.941 & -0.648 & 8.804 \\
Italy & 0.108 & 0.168 & -11.487 & 12.425 & 8.474 & -0.074 & 4.076 \\
U.K. & 0.152 & 0.273 & -24.862 & 7.947 & 5.257 & -1.760 & 21.482 \\
Germany & 0.196 & 0.269 & -14.079 & 11.945 & 7.667 & -0.497 & 4.934 \\
France & 0.169 & 0.162 & -11.972 & 9.904 & 7.512 & -0.133 & 3.899 \\
Portugal & 0.085 & 0.017 & -14.876 & 13.692 & 5.875 & -0.129 & 8.570 \\
Spain & 0.174 & 0.222 & -11.506 & 11.744 & 6.105 & -0.150 & 4.729 \\
Switzerland & 0.222 & 0.309 & -14.640 & 11.280 & 5.402 & -0.461 & 6.158 \\
Greece & 0.307 & -0.098 & -19.543 & 22.220 & 19.956 & 0.480 & 6.286 \\
\hline \hline
\end{tabular}

Notes to the table: all descriptive statistics are calculated using the sample sizes reported in Table 1; Mean $=\frac{1}{n} \sum_{t=1}^{n} y_{t} \equiv \hat{\mu} ;$ Med $=$ median; Min $=$ minimum value; $\operatorname{Max}=$ maximum value; $\operatorname{Var}=\frac{1}{n} \sum_{t=1}^{n}\left(y_{t}-\hat{\mu}\right)^{2} \equiv \hat{\sigma}^{2} ;$ Skew $=\frac{1}{n} \sum_{t=1}^{n} \frac{\left(y_{t}-\hat{\mu}\right)^{3}}{\hat{\sigma}^{3}} ;$ Kurt $=\frac{1}{n} \sum_{t=1}^{n} \frac{\left(y_{t}-\hat{\mu}\right)^{4}}{\hat{\sigma}^{4}}$. 
Table 3. Size of the rolling window for each stock price index

\begin{tabular}{ll}
\hline \hline \multicolumn{1}{c}{ Stock market } & Size of the rolling window \\
\hline Holland & 7 years, 365 weekly observ. \\
Belgium & 7 years, 365 weekly observ. \\
Germany & 7 years, 365 weekly observ. \\
U.K. & 7 years, 365 weekly observ. \\
Italy & 7 years, 365 weekly observ. \\
France & 363 weekly observations \\
Spain & 351 weekly observations \\
Portugal & 351 weekly observations \\
Switzerland & 338 weekly observations \\
Greece & 331 weekly observations \\
\hline
\end{tabular}

Notes to the table: For the last five indexes there is no correspondence with the number of years, since the rolling window doesn't exactly fit with an integer number of years.

Table 4. Classical evaluation criteria for each stock price index (continues)

\begin{tabular}{|c|c|c|c|c|c|c|c|c|c|c|c|c|c|c|}
\hline \multicolumn{8}{|c|}{ Holland } & \multicolumn{7}{|c|}{ Belgium } \\
\hline Model & $h$ MSPE & MedS & $2 \mathrm{H}$ & reat & $E D M$ & $S$ & $N W$ & MSPE & MedS & $M A$ & . & $D M$ & $S$ & $N W$ \\
\hline \multirow[t]{5}{*}{ GJR-G } & $\begin{array}{ll}1 & 0.993\end{array}$ & 931 & 994 & 0.965 & 0.426 & 0.565 & 0.459 & 963 & 0.889 & 0.982 & 0.943 & 0.113 & 0.374 & 0.309 \\
\hline & 20.990 & 0.930 & 0.994 & 0.964 & 0.408 & 0.432 & 0.471 & 948 & 0.937 & 0.970 & & 0.033 & 006 & .094 \\
\hline & 31.004 & 0.935 & 0.999 & 0.967 & 0.696 & .320 & 0.689 & & 0.932 & 0.976 & & 0.132 & .024 & .135 \\
\hline & 41.004 & 0.913 & 0.999 & 0.955 & 0.794 & & 0.793 & & & & & & & .108 \\
\hline & $\begin{array}{ll}5 & 1.003\end{array}$ & 0.913 & 1.000 & 0.956 & 0.663 & & 0.670 & 0.976 & 0.992 & 0.978 & 0.996 & 0.141 & 0.019 & 0.109 \\
\hline \multirow[t]{5}{*}{ Q-G } & 10.994 & 0.961 & 996 & 80 & 622 & 714 & 0.638 & 91 & 6 & 0.992 & 8 & 0.273 & .374 & .384 \\
\hline & 20.992 & 979 & 0.999 & 0.989 & 0.787 & 432 & 0.802 & & 0.990 & 0.985 & & 0.035 & 032 & .073 \\
\hline & 31.000 & 0.947 & 1.004 & 0.973 & 0.111 & 0.004 & 0.090 & & 0.950 & 0.989 & & 0.060 & .032 & .073 \\
\hline & 41.003 & 0.995 & 1.005 & 0.997 & 0.026 & 2 & 0.029 & & & & & & & .050 \\
\hline & $\begin{array}{ll}5 & 1.003\end{array}$ & 0.969 & & & & & & & & & & & & 0.047 \\
\hline \multirow[t]{5}{*}{ VS-G } & 11.023 & 687 & 936 & 329 & 0.131 & 794 & 0.037 & 4 & 0.625 & 0.935 & & 0.032 & 0.272 & 0.087 \\
\hline & 21.061 & 521 & 90 & 0.722 & 0.000 & 6 & 0.004 & & 0.501 & 0.886 & & 0.005 & 00 & .015 \\
\hline & 31.069 & 434 & 0.882 & 0.658 & 0.002 & 14 & 0.003 & 36 & 0.499 & 0.881 & & 0.013 & 00 & 0.012 \\
\hline & 41.065 & & 0.8 & & & & 0.003 & & & & & 21 & & .012 \\
\hline & $\begin{array}{ll}5 & 1.088\end{array}$ & t & 0.874 & 0.563 & 0.012 & 0.002 & 0.007 & 1.068 & 0.374 & 0.862 & 0.612 & 0.021 & 0.000 & 0.010 \\
\hline \multicolumn{8}{|c|}{ Germany } & \multicolumn{7}{|c|}{ U.K. } \\
\hline \multirow[t]{5}{*}{ GJR-G } & 10.990 & 0.898 & 0.988 & 0.948 & 0.484 & 105 & 0.394 & 056 & 0.927 & 1.019 & 0.963 & 0.145 & 0.794 & 0.208 \\
\hline & 20.969 & 0.911 & 0.983 & 55 & 0.125 & 20 & 0.205 & 10 & & 1.006 & & 0.514 & & 0.576 \\
\hline & 31.004 & 1.001 & 0.992 & 1.001 & 0.549 & 0.374 & 0.595 & 94 & 0.928 & 1.002 & & 0.499 & 0.875 & 0.506 \\
\hline & 40.996 & 0.898 & 0.986 & 0.948 & 0.412 & 0.875 & 0.378 & 0.974 & 0.893 & 0.994 & & 0.721 & 0.432 & 0.738 \\
\hline & $\begin{array}{ll}5 & 1.000\end{array}$ & 0.977 & 0.986 & 0.988 & 0.337 & 0.496 & 0.340 & 0.982 & 0.936 & 1.002 & 0.967 & 0.671 & 0.794 & 0.635 \\
\hline \multirow[t]{5}{*}{ Q-G } & 11.001 & 0.937 & 0.985 & 968 & 86 & 8 & 268 & 88 & 0 & 9 & 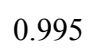 & 66 & 67 & .880 \\
\hline & 20.990 & 0.885 & 0.978 & 0.941 & 0.077 & 67 & 0.131 & 975 & 0.982 & 0.989 & & 0.480 & 053 & 0.520 \\
\hline & 31.004 & 0.972 & 0.984 & 0.986 & 0.282 & 0.794 & 0.313 & 0.974 & 1.020 & 0.991 & 1.010 & 0.607 & 0.032 & 0.609 \\
\hline & 41.006 & 0.908 & 0.981 & 0.953 & 0.341 & 0.958 & 0.280 & 0.974 & 0.930 & 0.986 & & 0.309 & 0.875 & 0.311 \\
\hline & $\begin{array}{ll}5 & 1.009\end{array}$ & 0.997 & 0.979 & 0.999 & 0.232 & 0.875 & 0.249 & 0.975 & 0.984 & 0.993 & 0.992 & 0.601 & 0.320 & 0.545 \\
\hline \multirow[t]{5}{*}{ VS-G } & 11.059 & 年 & . & & 7 & 1 & 0 & 1 & 2 & 3 & & 00 & 00 & .000 \\
\hline & 21.045 & 0.639 & 0.948 & 0.799 & 0.119 & 0.496 & 0.129 & 1.116 & 1.135 & 1.077 & 1.065 & 0.003 & 0.084 & 0.003 \\
\hline & 31.067 & 0.617 & 0.956 & 0.786 & 0.222 & 0.958 & 0.216 & 1.149 & 1.025 & 1.066 & 1.012 & 0.017 & 0.014 & 0.025 \\
\hline & 41.087 & 0.531 & 0.933 & 0.729 & 0.097 & 0.129 & 0.073 & 1.109 & 0.811 & 1.041 & & 0.122 & 0.320 & 0.142 \\
\hline & $\begin{array}{ll}5 & 1.108\end{array}$ & 0.530 & 0.944 & 0.728 & 0.156 & 0.041 & 0.143 & 1.141 & 0.633 & 1.022 & 0.796 & 0.417 & 0.958 & 0.380 \\
\hline
\end{tabular}




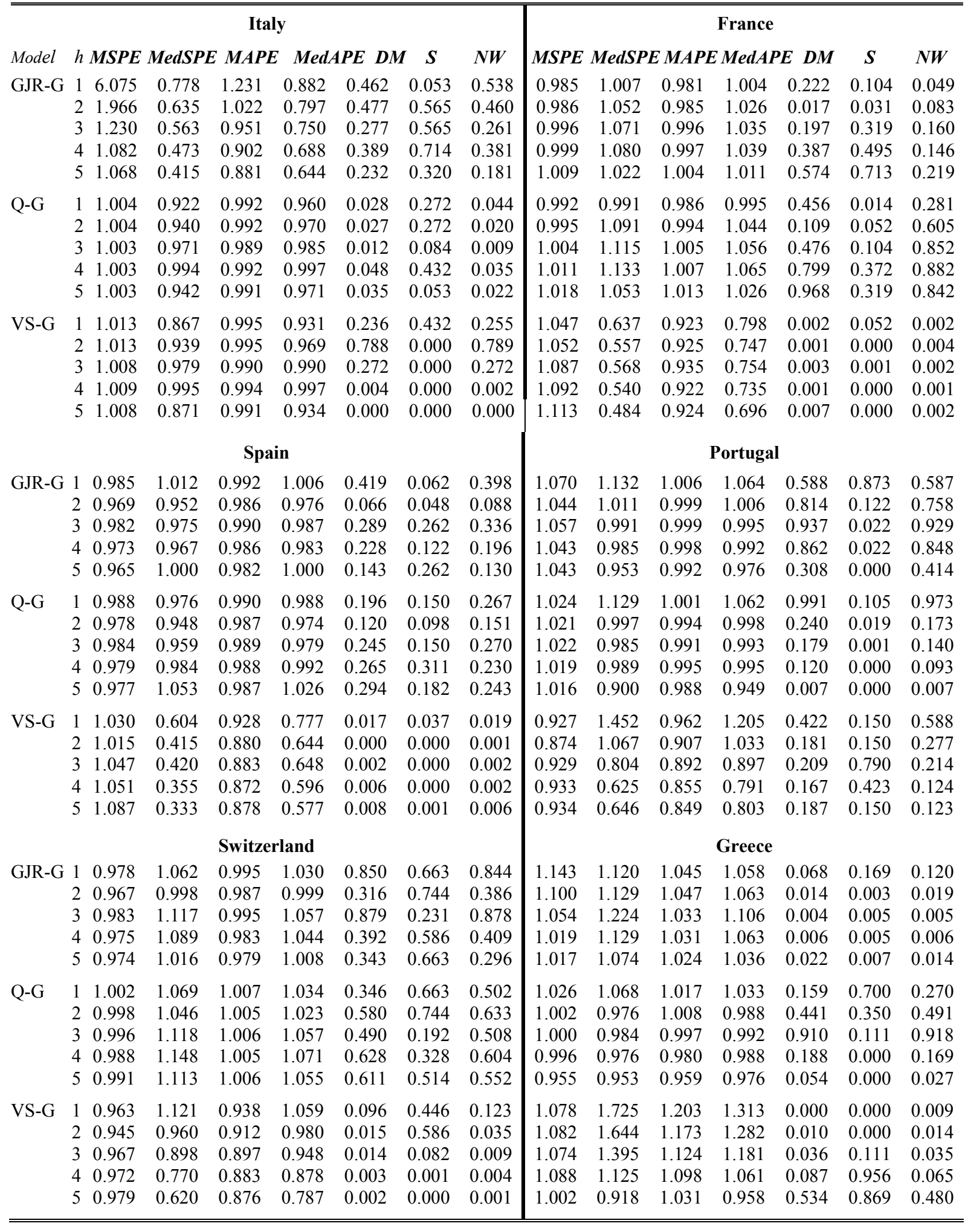

Notes to the table: For each stock index and each non-linear GARCH model, the entries of the first four columns are the calculated values from each evaluation criterion divided by the value taken by the same criterion when applied to the standard GARCH $(1,1)$ on the same forecasting horizon. 
Table 5. NW test after removing extreme observations

\begin{tabular}{lllllllllllll}
\hline \hline \multicolumn{10}{c}{ P-values of the NW test } \\
\hline Model & $h$ & Holland & Belgium & Germany & U.K. & Italy & France & Spain & Portugal Switzerl. & Greece \\
& & & & & & & & & & & \\
GJR-G & 1 & 0.861 & 0.768 & 0.161 & 0.543 & 0.875 & 0.058 & 0.077 & 0.248 & 0.656 & 0.059 \\
& 2 & 0.877 & 0.522 & 0.067 & 0.734 & 0.654 & 0.176 & 0.081 & 0.769 & 0.579 & 0.005 \\
& 3 & 0.696 & 0.127 & 0.433 & 0.722 & 0.622 & 0.059 & 0.102 & 0.472 & 0.812 & 0.006 \\
& 4 & 0.540 & 0.220 & 0.229 & 0.248 & 0.906 & 0.047 & 0.071 & 0.577 & 0.805 & 0.009 \\
& 5 & 0.951 & 0.496 & 0.239 & 0.142 & 0.416 & 0.126 & 0.246 & 0.280 & 0.776 & 0.056 \\
Q-G & 1 & 0.986 & 0.667 & 0.103 & 0.889 & 0.187 & 0.263 & 0.084 & 0.728 & 0.686 & 0.979 \\
& 2 & 0.287 & 0.456 & 0.479 & 0.920 & 0.125 & 0.948 & 0.714 & 0.073 & 0.448 & 0.349 \\
& 3 & 0.150 & 0.317 & 0.428 & 0.635 & 0.012 & 0.459 & 0.399 & 0.030 & 0.503 & 0.422 \\
& 4 & 0.016 & 0.220 & 0.511 & 0.325 & 0.132 & 0.534 & 0.423 & 0.008 & 0.599 & 0.039 \\
& 5 & 0.019 & 0.143 & 0.246 & 0.358 & 0.110 & 0.666 & 0.661 & 0.000 & 0.411 & 0.174 \\
VS-G & 1 & 0.095 & 0.120 & 0.281 & 0.000 & 0.991 & 0.014 & 0.021 & 0.530 & 0.307 & 0.000 \\
& 2 & 0.004 & 0.000 & 0.037 & 0.063 & 0.000 & 0.010 & 0.000 & 0.980 & 0.027 & 0.000 \\
& 3 & 0.007 & 0.005 & 0.045 & 0.107 & 0.000 & 0.001 & 0.000 & 0.648 & 0.006 & 0.018 \\
& 4 & 0.006 & 0.005 & 0.006 & 0.259 & 0.000 & 0.003 & 0.000 & 0.168 & 0.006 & 0.121 \\
& 5 & 0.007 & 0.007 & 0.012 & 0.766 & 0.000 & 0.000 & 0.001 & 0.261 & 0.005 & 0.547 \\
\hline \hline
\end{tabular}

Notes to the table: the NW test is a standard t-test of the null hypothesis of zero constant, with the variancecovariance matrix estimated using the Newey-West correction. Observations which exceed in absolute value three times the standard error of the loss differential have been removed.

Table 6a. Mincer-Zarnowitz regression

\begin{tabular}{|c|c|c|c|c|c|c|c|c|c|c|c|}
\hline \multicolumn{7}{|c|}{ Holland } & \multicolumn{5}{|c|}{ Belgium } \\
\hline Model & $h$ & 1 & 2 & 3 & 4 & 5 & 1 & 2 & 3 & 4 & 5 \\
\hline \multirow[t]{5}{*}{ GARCH } & $\mathrm{a}$ & 1.985 & 1.038 & 2.275 & 2.662 & 2.635 & 1.588 & 0.872 & 2.293 & 2.433 & 2.464 \\
\hline & & $(0.939)$ & $(0.953)$ & $(0.962)$ & $(0.964)$ & $(0.915)$ & $(0.761)$ & $(0.773)$ & $(0.825)$ & $(0.852)$ & $(0.876)$ \\
\hline & $\mathrm{b}$ & 0.671 & 0.615 & 0.551 & 0.552 & 0.813 & 0.126 & 0.131 & 0.144 & 0.152 & 0.159 \\
\hline & & $(0.103)$ & $(0.104)$ & $(0.105)$ & $(0.104)$ & $(0.100)$ & $(0.734)$ & $(0.895)$ & $(0.584)$ & $(0.557)$ & $(0.553)$ \\
\hline & $R^{2}$ & 0.104 & 0.153 & 0.088 & 0.071 & 0.072 & 0.086 & 0.113 & 0.043 & 0.036 & 0.032 \\
\hline \multirow[t]{5}{*}{ GJR-G } & $\mathrm{a}$ & 1.977 & 1.054 & 2.408 & 2.772 & 2.740 & 1.136 & 0.052 & 1.909 & 2.020 & 1.899 \\
\hline & & $(0.925)$ & $(0.900)$ & $(0.940)$ & $(0.949)$ & $(0.949)$ & $(0.746)$ & $(0.756)$ & $(0.834)$ & $(0.872)$ & $(0.907)$ \\
\hline & $\mathrm{b}$ & 0.675 & 0.814 & 0.597 & 0.537 & 0.539 & 0.859 & 1.117 & 0.699 & 0.682 & 0.717 \\
\hline & & $(0.101)$ & $(0.098)$ & $(0.102)$ & $(0.102)$ & $(0.102)$ & $(0.127)$ & $(0.134)$ & $(0.153)$ & $(0.166)$ & $(0.177)$ \\
\hline & $R^{2}$ & 0.109 & 0.160 & 0.087 & 0.071 & 0.072 & 0.112 & 0.161 & 0.054 & 0.044 & 0.043 \\
\hline \multirow[t]{5}{*}{ QG } & $\mathrm{a}$ & 1.971 & 1.041 & 2.310 & 2.698 & 2.669 & 1.517 & 0.660 & 2.169 & 2.293 & 2.308 \\
\hline & & $(0.926)$ & $(0.901)$ & $(0.940)$ & $(0.950)$ & $(0.952)$ & $(0.756)$ & $(0.768)$ & $(0.827)$ & $(0.857)$ & $(0.884)$ \\
\hline & $\mathrm{b}$ & 0.669 & 0.804 & 0.602 & 0.538 & 0.538 & 0.766 & 0.961 & 0.628 & 0.603 & 0.607 \\
\hline & & $(0.100)$ & $(0.097)$ & $(0.100)$ & $(0.101)$ & $(0.100)$ & $(0.127)$ & $(0.133)$ & $(0.148)$ & $(0.158)$ & $(0.167)$ \\
\hline & $R^{2}$ & 0.109 & 0.159 & 0.090 & 0.073 & 0.073 & 0.091 & 0.125 & 0.047 & 0.039 & 0.035 \\
\hline \multirow[t]{5}{*}{ VS-G } & $\mathrm{a}$ & 1.744 & -1.549 & 2.020 & 2.741 & 4.014 & 1.254 & -2.022 & 0.934 & 0.869 & -0.379 \\
\hline & & $(1.027)$ & $(1.059)$ & $(1.248)$ & (1.332) & (1.372) & $(0.790)$ & $(0.789)$ & $(0.983)$ & (1.132) & (1.309) \\
\hline & $\mathrm{b}$ & 1.101 & 2.194 & 1.343 & 1.230 & 0.852 & 1.146 & 2.521 & 1.655 & 1.878 & 2.687 \\
\hline & & $(0.188)$ & $(0.238)$ & $(0.330)$ & $(0.399)$ & $(0.450)$ & $(0.190)$ & $(0.234)$ & $(0.349)$ & $(0.467)$ & $(0.610)$ \\
\hline & $R^{2}$ & 0.086 & 0.189 & 0.043 & 0.025 & 0.010 & 0.091 & 0.242 & 0.058 & 0.043 & 0.051 \\
\hline
\end{tabular}

Notes to the table: $a$ and $b$ are Ordinary Least Squares estimates of the parameters in regression (9); standard errors calculated using the Newey-West correction are reported in parentheses. 
Table 6b. Mincer-Zarnowitz regression

\begin{tabular}{|c|c|c|c|c|c|c|c|c|c|c|c|}
\hline \multicolumn{7}{|c|}{ Germany } & \multicolumn{5}{|c|}{ U.K. } \\
\hline Model & $h$ & 1 & 2 & 3 & 4 & 5 & 1 & 2 & 3 & 4 & 5 \\
\hline \multirow[t]{5}{*}{ GARCH } & $\mathrm{a}$ & 2.458 & 1.218 & 3.263 & 2.716 & 2.443 & 2.547 & 1.643 & 2.097 & 1.377 & 1.699 \\
\hline & & $(1.416)$ & $(1.422)$ & (1.487) & $(1.509)$ & $(1.536)$ & $(0.839)$ & $(0.878)$ & $(0.900)$ & $(0.896)$ & $(0.898)$ \\
\hline & $\mathrm{b}$ & 0.740 & 0.904 & 0.636 & 0.709 & 0.747 & 0.415 & 0.595 & 0.493 & 0.632 & 0.563 \\
\hline & & $(0.150)$ & $(0.153)$ & $(0.162)$ & $(0.166)$ & $(0.172)$ & $(0.159)$ & $(0.166)$ & $(0.168)$ & $(0.166)$ & $(0.165)$ \\
\hline & $R^{2}$ & 0.063 & 0.088 & 0.041 & 0.047 & 0.049 & 0.018 & 0.034 & 0.023 & 0.038 & 0.031 \\
\hline \multirow[t]{5}{*}{ GJR-G } & $\mathrm{a}$ & 2.195 & -0.151 & 3.470 & 2.271 & 1.904 & 3.107 & 2.080 & 2.141 & 1.247 & 1.616 \\
\hline & & $(1.408)$ & $(1.430)$ & (1.566) & $(1.628)$ & $(1.705)$ & $(0.667)$ & $(0.723)$ & $(0.769)$ & $(0.785)$ & $(0.807)$ \\
\hline & $\mathrm{b}$ & 0.805 & 1.141 & 0.648 & 0.826 & 0.888 & 0.284 & 0.488 & 0.469 & 0.642 & 0.565 \\
\hline & & $(0.155)$ & $(0.163)$ & $(0.185)$ & $(0.199)$ & $(0.215)$ & $(0.114)$ & $(0.126)$ & $(0.135)$ & $(0.138)$ & $(0.142)$ \\
\hline & $R^{2}$ & 0.069 & 0.118 & 0.033 & 0.045 & 0.045 & 0.017 & 0.040 & 0.032 & 0.056 & 0.042 \\
\hline \multirow[t]{5}{*}{ QG } & $\mathrm{a}$ & 2.202 & -0.215 & 3.206 & 2.261 & 85 & 2.510 & 1.280 & 1.745 & 0.912 & 1.335 \\
\hline & & $(1.484)$ & $(1.531)$ & (1.680) & (1.769) & $(1.868)$ & $(0.832)$ & $(0.905)$ & $(0.953)$ & $(0.967)$ & $(0.987)$ \\
\hline & $\mathrm{b}$ & 0.825 & 1.180 & 0.702 & 0.846 & 0.924 & 0.421 & 0.674 & 0.576 & 0.751 & 0.656 \\
\hline & & $(0.171)$ & $(0.184)$ & $(0.209)$ & $(0.227)$ & $(0.246)$ & $(0.158)$ & $(0.174)$ & $(0.184)$ & $(0.187)$ & $(0.192)$ \\
\hline & $R^{2}$ & 0.060 & 0.102 & 0.030 & 0.037 & 0.037 & 0.019 & 0.039 & 0.026 & 0.042 & 0.031 \\
\hline \multirow[t]{6}{*}{ VS-G } & $\mathrm{a}$ & 4.236 & -1.797 & 5.419 & 4.174 & 5.853 & 3.378 & 3.238 & 4.074 & 3.263 & 3.906 \\
\hline & & (1.539) & $(1.687)$ & $(2.056)$ & $(2.346)$ & $(2.616)$ & $(0.706)$ & $(0.705)$ & $(0.697)$ & $(0.676)$ & $(0.659)$ \\
\hline & $\mathrm{b}$ & 0.727 & 2.049 & 0.596 & 0.933 & 0.555 & 0.205 & 0.241 & 0.083 & 0.253 & 0.121 \\
\hline & & $(0.241)$ & $(0.307)$ & $(0.420)$ & $(0.524)$ & $(0.624)$ & $(0.110)$ & $(0.115)$ & $(0.118)$ & $(0.117)$ & $(0.117)$ \\
\hline & $R^{2}$ & 0.024 & 0.109 & 0.005 & 0.009 & 0.002 & 0.009 & 0.012 & 0.001 & 0.013 & 0.003 \\
\hline & & & Italy & & & & & & France & & \\
\hline \multirow[t]{5}{*}{ GARCH } & $\mathrm{a}$ & 5.036 & 4.392 & 4.943 & 4.615 & 3.706 & 3.605 & 2.138 & 3.502 & 3.665 & 4.176 \\
\hline & & $(2.283)$ & $(2.335)$ & $(2.397)$ & $(2.453)$ & $(2.507)$ & (1.754) & (1.778) & $(1.822)$ & (1.857) & (1.892) \\
\hline & $\mathrm{b}$ & 0.462 & 0.530 & 0.471 & 0.507 & 0.600 & 0.575 & 0.775 & 0.583 & 0.563 & 0.497 \\
\hline & & $(0.232)$ & $(0.238)$ & $(0.245)$ & $(0.251)$ & $(0.257)$ & $(0.219)$ & $(0.224)$ & $(0.231)$ & $(0.236)$ & $(0.242)$ \\
\hline & $R^{2}$ & 0.011 & 0.013 & 0.010 & 0.011 & 0.015 & 0.019 & 0.032 & 0.017 & 0.015 & 0.012 \\
\hline \multirow[t]{5}{*}{ GJR-G } & $\mathrm{a}$ & 6.200 & 5.650 & 5.141 & 5.577 & 4.576 & 2.667 & 1.145 & 2.929 & 3.202 & 4.211 \\
\hline & & $(2.248)$ & $(2.305)$ & $(2.368)$ & $(2.430)$ & $(2.489)$ & $(1.725)$ & $(1.750)$ & $(1.808)$ & (1.851) & (1.899) \\
\hline & $\mathrm{b}$ & 0.344 & 0.405 & 0.395 & 0.414 & 0.520 & 0.712 & 0.928 & 0.682 & 0.644 & 0.509 \\
\hline & & $(0.233)$ & $(0.240)$ & $(0.248)$ & $(0.255)$ & $(0.262)$ & $(0.222)$ & $(0.227)$ & $(0.236)$ & $(0.242)$ & $(0.250)$ \\
\hline & $R^{2}$ & 0.006 & 0.008 & 0.007 & 0.007 & 0.011 & 0.028 & 0.044 & 0.023 & 0.019 & 0.011 \\
\hline \multirow[t]{5}{*}{ QG } & $\mathrm{a}$ & 5.349 & 4.744 & 5.189 & 4.911 & 3.930 & 3.214 & 1.975 & 3.558 & 4.083 & 4.826 \\
\hline & & $(2.303)$ & $(2.362)$ & $(2.429)$ & $(2.494)$ & $(2.555)$ & $(1.628)$ & $(1.661)$ & $(1.721)$ & (1.771) & (1.823) \\
\hline & $\mathrm{b}$ & 0.436 & 0.502 & 0.454 & 0.485 & 0.588 & 0.638 & 0.814 & 0.596 & 0.522 & 0.425 \\
\hline & & $(0.238)$ & $(0.245)$ & $(0.253)$ & $(0.261)$ & $(0.268)$ & $(0.208)$ & $(0.213)$ & $(0.222)$ & $(0.230)$ & $(0.238)$ \\
\hline & $R^{2}$ & 0.009 & 0.011 & 0.009 & 0.009 & 0.013 & 0.025 & 0.039 & 0.019 & 0.014 & 0.009 \\
\hline \multirow[t]{5}{*}{ VS-G } & $\mathrm{a}$ & 9.278 & 9.115 & 9.551 & 9.139 & 7.920 & 5.068 & 0.814 & 6.672 & 4.661 & 10.715 \\
\hline & & $(0.861)$ & $(0.932)$ & $(1.155)$ & $(1.730)$ & $(2.671)$ & $(1.871)$ & $(2.133)$ & $(2.450)$ & $(2.678)$ & (2.819) \\
\hline & $\mathrm{b}$ & 0.001 & 0.019 & -0.040 & 0.023 & 0.240 & 0.510 & 1.378 & 0.253 & 0.708 & -0.647 \\
\hline & & $(0.023)$ & $(0.052)$ & $(0.118)$ & $(0.254)$ & $(0.470)$ & $(0.320)$ & $(0.401)$ & $(0.496)$ & $(0.573)$ & $(0.631)$ \\
\hline & $R^{2}$ & 0.000 & 0.000 & 0.000 & 0.000 & 0.001 & 0.007 & 0.032 & 0.001 & 0.004 & 0.003 \\
\hline
\end{tabular}

Notes to the table: see Table $6 \mathrm{a}$. 
Table 6c. Mincer-Zarnowitz regression

\begin{tabular}{|c|c|c|c|c|c|c|c|c|c|c|c|}
\hline \multicolumn{7}{|c|}{ Spain } & \multicolumn{5}{|c|}{ Portugal } \\
\hline Model & $h$ & 1 & 2 & 3 & 4 & 5 & 1 & 2 & 3 & 4 & 5 \\
\hline \multirow[t]{5}{*}{ GARCH } & $\mathrm{a}$ & 2.321 & 1.441 & 2.474 & 2.719 & 1.798 & 2.481 & 2.615 & 4.334 & 4.536 & 4.592 \\
\hline & & (1.177) & $(1.185)$ & $(1.226)$ & $(1.251)$ & $(1.255)$ & (1.168) & (1.187) & $(1.230)$ & $(1.242)$ & $(1.251)$ \\
\hline & $\mathrm{b}$ & 0.667 & 0.810 & 0.651 & 0.617 & 0.756 & 0.590 & 0.565 & 0.312 & 0.280 & 0.271 \\
\hline & & $(0.142)$ & $(0.144)$ & $(0.150)$ & $(0.154)$ & $(0.156)$ & $(0.104)$ & $(0.106)$ & $(0.110)$ & $(0.110)$ & $(0.111)$ \\
\hline & $R^{2}$ & 0.060 & 0.083 & 0.051 & 0.044 & 0.063 & 0.084 & 0.075 & 0.023 & 0.018 & 0.017 \\
\hline \multirow[t]{5}{*}{ GJR-G } & $\mathrm{a}$ & 2.065 & 0.765 & 2.056 & 1.986 & 0.671 & 3.304 & 3.104 & 5.313 & 5.329 & 5.427 \\
\hline & & $(1.156)$ & $(1.161)$ & $(1.220)$ & $(1.252)$ & $(1.261)$ & $(1.202)$ & $(1.212)$ & $(1.249)$ & $(1.257)$ & $(1.264)$ \\
\hline & $\mathrm{b}$ & 0.718 & 0.932 & 0.734 & 0.751 & 0.960 & 0.475 & 0.502 & 0.176 & 0.173 & 0.159 \\
\hline & & $(0.140)$ & $(0.144)$ & $(0.153)$ & $(0.160)$ & $(0.164)$ & $(0.109)$ & $(0.110)$ & $(0.114)$ & $(0.114)$ & $(0.115)$ \\
\hline & $R^{2}$ & 0.070 & 0.108 & 0.061 & 0.059 & 0.089 & 0.051 & 0.056 & 0.007 & 0.006 & 0.005 \\
\hline \multirow[t]{5}{*}{ QG } & $\mathrm{a}$ & 2.131 & 1.010 & 2.129 & 2.197 & 1.099 & 2.650 & 2.711 & 4.494 & 4.752 & 4.856 \\
\hline & & $(1.160)$ & (1.167) & (1.218) & $(1.248)$ & $(1.257)$ & (1.131) & $(1.150)$ & (1.192) & $(1.205)$ & $(1.213)$ \\
\hline & $\mathrm{b}$ & 0.708 & 0.893 & 0.720 & 0.714 & 0.885 & 0.558 & 0.542 & 0.266 & 0.237 & 0.227 \\
\hline & & $(0.141)$ & $(0.144)$ & $(0.152)$ & $(0.158)$ & $(0.161)$ & $(0.104)$ & $(0.107)$ & $(0.111)$ & $(0.112)$ & $(0.113)$ \\
\hline & $R^{2}$ & 0.067 & 0.099 & 0.060 & 0.055 & 0.079 & 0.073 & 0.066 & 0.016 & 0.012 & 0.011 \\
\hline \multirow[t]{5}{*}{ VS-G } & $\mathrm{a}$ & 3.257 & -0.621 & 1.257 & -0.286 & -3.803 & 2.088 & 0.439 & 4.278 & 4.903 & 4.466 \\
\hline & & (1.139) & $(1.185)$ & (1.382) & $(1.536)$ & $(1.658)$ & (1.103) & $(1.147)$ & $(1.355)$ & (1.499) & $(1.647)$ \\
\hline & $b$ & 0.792 & 1.987 & 1.687 & 2.402 & 3.906 & 0.802 & 1.277 & 0.528 & 0.421 & 0.585 \\
\hline & & $(0.203)$ & $(0.260)$ & $(0.362)$ & $(0.462)$ & $(0.557)$ & $(0.115)$ & $(0.154)$ & $(0.225)$ & $(0.297)$ & $(0.372)$ \\
\hline & $R^{2}$ & 0.042 & 0.143 & 0.059 & 0.072 & 0.123 & 0.123 & 0.165 & 0.015 & 0.006 & 0.007 \\
\hline \multicolumn{7}{|c|}{ Switzerland } & \multicolumn{5}{|c|}{ Greece } \\
\hline \multirow[t]{5}{*}{ GARCH } & $\mathrm{a}$ & 2.403 & 2.245 & 3.965 & 3.903 & 3.778 & 16.267 & 15.951 & 14.134 & 9.855 & 16.867 \\
\hline & & $(1.170)$ & $(1.174)$ & (1.212) & $(1.218)$ & $(1.224)$ & $(4.024)$ & $(4.328)$ & $(4.650)$ & $(4.960)$ & $(5.341)$ \\
\hline & $\mathrm{b}$ & 0.658 & 0.688 & 0.407 & 0.426 & 0.447 & 0.185 & 0.197 & 0.268 & 0.437 & 0.151 \\
\hline & & $(0.133)$ & $(0.135)$ & $(0.140)$ & $(0.142)$ & $(0.143)$ & $(0.128)$ & $(0.143)$ & $(0.157)$ & $(0.169)$ & $(0.183)$ \\
\hline & $R^{2}$ & 0.068 & 0.072 & 0.024 & 0.026 & 0.028 & 0.006 & 0.006 & 0.009 & 0.020 & 0.002 \\
\hline \multirow[t]{5}{*}{ GJR-G } & $\mathrm{a}$ & 1.904 & 1.431 & 3.696 & 3.440 & 3.252 & 17.506 & 17.752 & 15.889 & 10.922 & 16.346 \\
\hline & & (1.178) & $(1.188)$ & (1.251) & (1.269) & (1.289) & (3.539) & $(3.848)$ & (4.198) & $(4.576)$ & $(5.059)$ \\
\hline & $b$ & 0.735 & 0.823 & 0.454 & 0.509 & 0.545 & 0.122 & 0.114 & 0.185 & 0.378 & 0.165 \\
\hline & & $(0.135)$ & $(0.140)$ & $(0.151)$ & $(0.156)$ & $(0.162)$ & $(0.093)$ & $(0.110)$ & $(0.128)$ & $(0.146)$ & $(0.166)$ \\
\hline & $R^{2}$ & 0.081 & 0.093 & 0.026 & 0.030 & 0.032 & 0.005 & 0.003 & 0.006 & 0.020 & 0.003 \\
\hline \multirow[t]{5}{*}{ QG } & $\mathrm{a}$ & 2.271 & 1.972 & 3.889 & 3.618 & 3.551 & 17.567 & 17.051 & 16.074 & 11.447 & 12.856 \\
\hline & & $(1.201)$ & $(1.210)$ & (1.254) & $(1.265)$ & $(1.278)$ & (3.924) & (4.316) & $(4.743)$ & $(5.142)$ & $(5.546)$ \\
\hline & $b$ & 0.665 & 0.717 & 0.408 & 0.460 & 0.471 & 0.124 & 0.148 & 0.190 & 0.385 & 0.324 \\
\hline & & $(0.137)$ & $(0.140)$ & $(0.147)$ & $(0.150)$ & $(0.153)$ & $(0.121)$ & $(0.144)$ & $(0.166)$ & $(0.185)$ & $(0.203)$ \\
\hline & $R^{2}$ & 0.065 & 0.072 & 0.022 & 0.027 & 0.027 & 0.003 & 0.003 & 0.004 & 0.013 & 0.008 \\
\hline \multirow[t]{5}{*}{ VS-G } & $\mathrm{a}$ & 1.112 & -1.130 & 2.802 & 1.736 & 0.353 & 13.728 & 14.970 & 14.533 & 14.315 & 13.135 \\
\hline & & $(1.245)$ & $(1.285)$ & (1.477) & $(1.602)$ & $(1.752)$ & $(4.153)$ & $(4.238)$ & $(4.316)$ & $(4.396)$ & $(4.472)$ \\
\hline & $\mathrm{b}$ & 1.015 & 1.639 & 0.875 & 1.255 & 1.754 & 0.208 & 0.178 & 0.202 & 0.219 & 0.273 \\
\hline & & $(0.177)$ & $(0.217)$ & $(0.290)$ & $(0.358)$ & $(0.439)$ & $(0.100)$ & (0.109) & $(0.117)$ & $(0.126)$ & $(0.134)$ \\
\hline & $R^{2}$ & 0.089 & 0.145 & 0.026 & 0.035 & 0.045 & 0.013 & 0.008 & 0.009 & 0.009 & 0.012 \\
\hline
\end{tabular}

Notes to the table: see Table $6 \mathrm{a}$. 
Table 7. Weights of the forecast combination (constant coefficients)

\begin{tabular}{|c|c|c|c|c|c|c|c|c|c|c|}
\hline \multicolumn{6}{|c|}{ Holland } & \multicolumn{5}{|c|}{ Belgium } \\
\hline Model & 1 & 2 & 3 & 4 & 5 & 1 & 2 & 3 & 4 & 5 \\
\hline Const. & 1.448 & -2.411 & 0.730 & 1.771 & 2.539 & 1.508 & -4.417 & 0.924 & 1.565 & 0.172 \\
\hline GARCH & -2.386 & -0.141 & -1.383 & -1.663 & -1.448 & -0.865 & 3.950 & -0.260 & -1.007 & -0.761 \\
\hline GJR-G & -1.167 & -0.791 & -12.320 & -6.799 & -7.750 & 5.762 & 0.379 & -1.204 & 0.441 & -0.110 \\
\hline QG & 4.043 & 1.284 & 14.221 & 8.937 & 9.837 & -3.556 & -5.321 & 1.150 & 0.798 & 0.789 \\
\hline VS-G & 0.476 & 1.819 & 0.470 & 0.374 & -0.258 & -0.701 & 4.942 & 2.068 & 1.030 & 2.481 \\
\hline$R^{2}$ & 0.139 & 0.236 & 0.155 & 0.097 & 0.120 & 0.176 & 0.384 & 0.038 & 0.025 & 0.031 \\
\hline \multicolumn{6}{|c|}{ Germany } & \multicolumn{5}{|c|}{ U.K. } \\
\hline Const. & 3.845 & -5.339 & 1.815 & 3.103 & 5.487 & 2.341 & 0.938 & 2.318 & 2.394 & 2.450 \\
\hline GARCH & -0.949 & 0.037 & 1.282 & 0.541 & 1.525 & 0.170 & -0.023 & -0.130 & -0.031 & 0.276 \\
\hline GJR-G & 3.531 & 1.770 & 0.365 & 1.727 & 2.076 & 0.030 & 0.020 & 0.990 & 1.827 & 1.712 \\
\hline QG & -1.846 & -1.442 & -1.456 & -1.739 & -3.190 & 0.460 & 0.692 & -0.041 & -0.801 & -0.881 \\
\hline VS-G & -0.364 & 2.060 & 0.837 & 0.109 & -0.334 & -0.227 & 0.024 & -0.411 & -0.657 & -0.800 \\
\hline$R^{2}$ & 0.097 & 0.206 & 0.026 & 0.038 & 0.053 & 0.031 & 0.055 & 0.062 & 0.115 & 0.101 \\
\hline \multicolumn{6}{|c|}{ Italy } & \multicolumn{5}{|c|}{ France } \\
\hline Const. & 6.155 & $4.928^{\circ}$ & 6.204 & 5.365 & 4.398 & -2.161 & -6.794 & -1.476 & 1.313 & 3.417 \\
\hline GARCH & 0.721 & 1.029 & 1.391 & 0.801 & 0.530 & -0.212 & -0.268 & -0.017 & -0.636 & -0.917 \\
\hline GJR-G & -0.802 & -0.632 & 0.423 & -0.130 & -0.118 & 1.702 & 2.934 & 1.235 & 2.562 & 2.525 \\
\hline QG & 0.481 & 0.107 & -1.397 & -0.078 & 0.402 & -0.745 & -1.746 & -0.415 & -1.116 & -0.726 \\
\hline VS-G & 0.000 & 0.025 & -0.040 & -0.130 & -0.308 & 0.904 & 1.689 & 0.811 & 0.247 & -0.345 \\
\hline$R^{2}$ & 0.012 & 0.017 & 0.010 & 0.014 & 0.021 & 0.075 & 0.119 & 0.051 & 0.043 & 0.046 \\
\hline \multicolumn{6}{|c|}{ Spain } & \multicolumn{5}{|c|}{ Portugal } \\
\hline Const. & 2.995 & -2.194 & 1.223 & -1.362 & -6.802 & 3.244 & 0.325 & 7.738 & 7.994 & 7.271 \\
\hline GARCH & -1.535 & 0.795 & -1.285 & -1.344 & -0.375 & 3.203 & 4.209 & 7.781 & 9.584 & 10.118 \\
\hline GJR-G & 2.025 & -1.691 & -1.711 & -2.373 & -0.119 & -7.768 & 0.393 & -8.254 & -4.487 & -4.524 \\
\hline QG & 0.573 & 0.780 & 3.492 & 3.780 & 0.343 & 4.902 & -4.605 & 0.713 & -5.004 & -5.645 \\
\hline VS-G & -0.634 & 2.705 & 0.923 & 2.937 & 5.739 & 0.182 & 1.199 & -0.777 & -0.887 & -0.624 \\
\hline$R^{2}$ & 0.090 & 0.184 & 0.087 & 0.112 & 0.192 & 0.284 & 0.214 & 0.281 & 0.209 & 0.220 \\
\hline \multicolumn{6}{|c|}{ Switzerland } & \multicolumn{5}{|c|}{ Greece } \\
\hline Const. & 2.126 & -0.348 & 3.718 & 2.088 & 0.547 & 11.020 & 9.981 & 9.786 & 9.729 & 11.289 \\
\hline GARCH & 1.007 & 0.827 & 1.081 & 0.158 & 0.330 & 0.454 & 1.308 & 1.585 & 0.516 & -1.445 \\
\hline GJR-G & 0.479 & -0.264 & -0.087 & -0.210 & -0.248 & 0.336 & -0.349 & -0.291 & 0.411 & 0.745 \\
\hline QG & -1.208 & -0.704 & -0.854 & 0.132 & -0.141 & -0.868 & -0.824 & -1.311 & -0.809 & 0.702 \\
\hline VS-G & 0.636 & 1.841 & 0.652 & 1.256 & 2.104 & 0.328 & 0.246 & 0.360 & 0.226 & 0.326 \\
\hline$R^{2}$ & 0.093 & 0.153 & 0.036 & 0.044 & 0.060 & 0.032 & 0.031 & 0.046 & 0.039 & 0.031 \\
\hline
\end{tabular}


Table 8a. Forecast combination with constant weights and Mincer-Zarnowitz regression

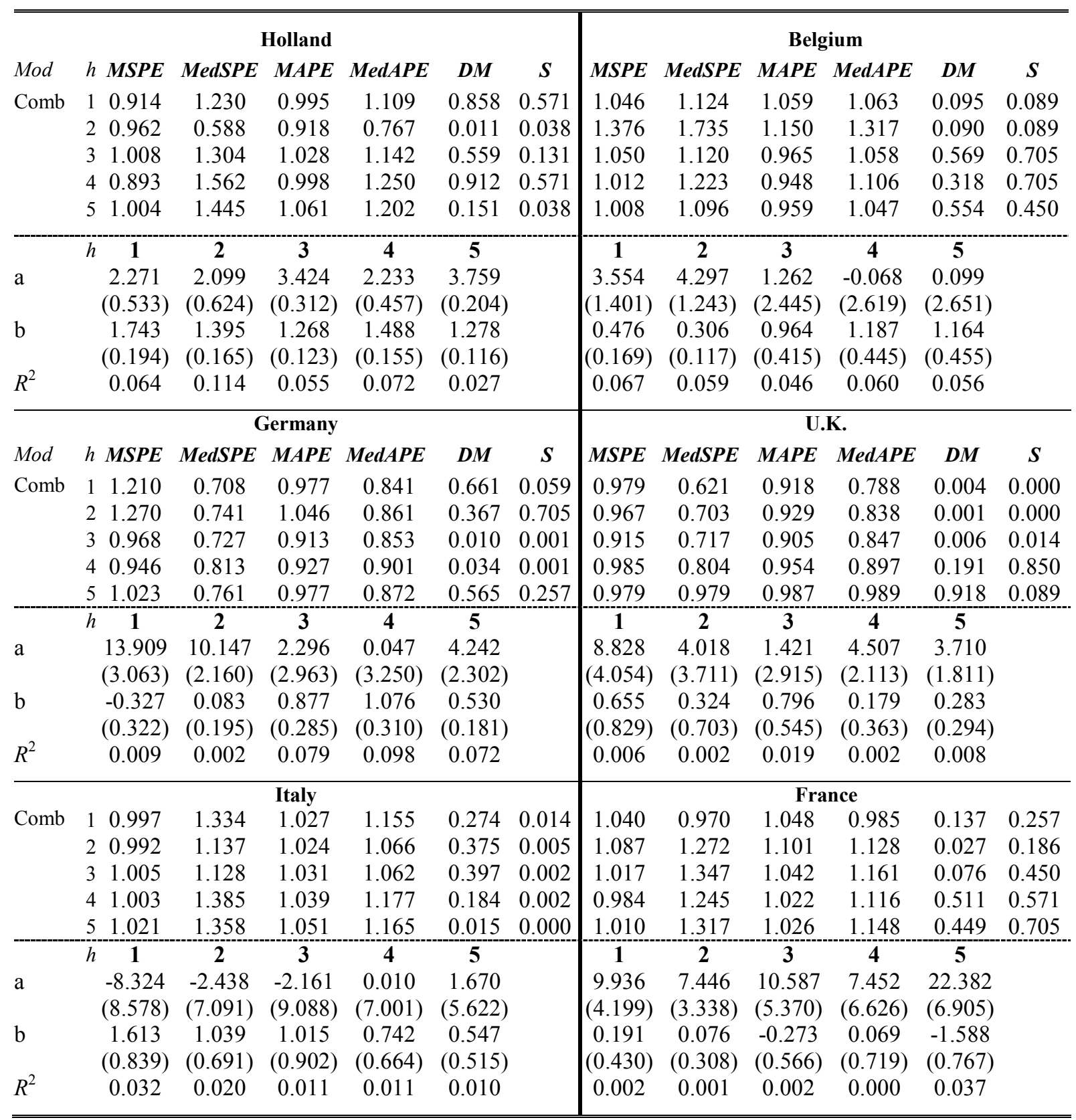

Notes to the table: each section is relative to a specific stock index and it is divided in two parts. The upper part is devoted to forecast evaluation, while the lower part is dedicated to the Mincer-Zarnowitz regression 
Table 8b. Forecast combination with constant weights and Mincer-Zarnowitz regression

\begin{tabular}{|c|c|c|c|c|c|c|c|c|c|c|c|c|}
\hline & & & Spain & & & & & & Port & ugal & & \\
\hline Comb & 10.976 & 1.232 & 1.035 & 1.110 & 0.046 & 0.089 & 0.949 & 1.230 & 0.954 & 1.109 & 0.145 & 0.571 \\
\hline & 21.079 & 0.957 & 1.059 & 0.978 & 0.245 & 0.450 & 1.248 & 1.119 & 1.145 & 1.057 & 0.006 & 0.008 \\
\hline & 31.004 & 1.643 & 1.090 & 1.282 & 0.016 & 0.008 & 1.057 & 1.954 & 1.081 & 1.398 & 0.131 & 0.059 \\
\hline & 41.197 & 1.772 & 1.182 & 1.331 & 0.011 & 0.005 & 1.282 & 2.348 & 1.185 & 1.532 & 0.008 & 0.008 \\
\hline & 51.397 & 1.434 & 1.247 & 1.197 & 0.011 & 0.005 & 1.358 & 2.245 & 1.202 & 1.498 & 0.026 & 0.001 \\
\hline & $h$ & 2 & 3 & 4 & 5 & & 1 & 2 & 3 & 4 & 5 & \\
\hline $\mathrm{a}$ & 5.395 & 5.104 & 5.817 & 8.142 & 7.211 & & 2.921 & 5.393 & 0.3 & 9.762 & 9.739 & \\
\hline & (2.897) & (1.709) & $(2.547)$ & (1.988) & (1.528) & & $(2.170)$ & $(1.348)$ & $(3.302)$ & $(2.087)$ & (1.693) & \\
\hline $\mathrm{b}$ & 0.135 & 0.191 & 0.114 & -0.135 & -0.025 & & 0.432 & 0.021 & -0.139 & -0.629 & -0.649 & \\
\hline & $(0.389)$ & $(0.186)$ & $(0.292)$ & $(0.197)$ & $(0.135)$ & & $(0.357)$ & $(0.180)$ & $(0.478)$ & $(0.277)$ & $(0.226)$ & \\
\hline$R^{2}$ & 0.001 & 0.009 & 0.001 & 0.004 & 0.000 & & 0.013 & 0.000 & 0.001 & 0.045 & 0.069 & \\
\hline & & & witze & & & & & & & & & \\
\hline Comb & 11.007 & 2.151 & 1.105 & 1.468 & 0.000 & 0.000 & 0.951 & 0.500 & 0.877 & 0.707 & 0.001 & 0.008 \\
\hline & 20.989 & 2.016 & 1.1 & 1.420 & 0.001 & 0.000 & 0.965 & 0.591 & 0.901 & 69 & 0.002 & 0.002 \\
\hline & 30.993 & 2.593 & 1.145 & 1.610 & 0.001 & 0.000 & 1.005 & 0.542 & 0.921 & 0.737 & 0.047 & 0.014 \\
\hline & 41.001 & 2.329 & 1.169 & 1.526 & 0.006 & 0.000 & 0.990 & 0.490 & 0.871 & 0.700 & 0.000 & 0.000 \\
\hline & 51.122 & 2.724 & 1.272 & 1.651 & 0.000 & 0.000 & 0.973 & 0.362 & 0.872 & 0.601 & 0.002 & 0.000 \\
\hline & 1 & 2 & 3 & 4 & 5 & & 1 & 2 & 3 & 4 & 5 & \\
\hline $\mathrm{a}$ & -1.701 & -0.009 & 8.401 & 7.216 & 10.195 & & 11.910 & 25.296 & 32.050 & 43.502 & 17.077 & \\
\hline & (2.164) & (1.838) & $(3.531)$ & $(3.631)$ & $(3.481)$ & & $(10.670)$ & (14.924) & $(12.526)$ & (18.767) & $(11.816)$ & \\
\hline b & 0.939 & 0.648 & -0.529 & -0.337 & -0.669 & & 0.517 & -0.049 & -0.305 & -0.781 & 0.386 & \\
\hline & $(0.309)$ & $(0.235)$ & $(0.487)$ & $(0.466)$ & $(0.410)$ & & $(0.411)$ & $(0.577)$ & $(0.478)$ & $(0.809)$ & $(0.477)$ & \\
\hline$R^{2}$ & 0.077 & 0.064 & 0.011 & 0.005 & 0.023 & & 0.014 & 0.000 & 0.004 & 0.008 & 0.006 & \\
\hline
\end{tabular}

Notes to the table: see Table 8a.

Temporal evolution of the five combination coefficients
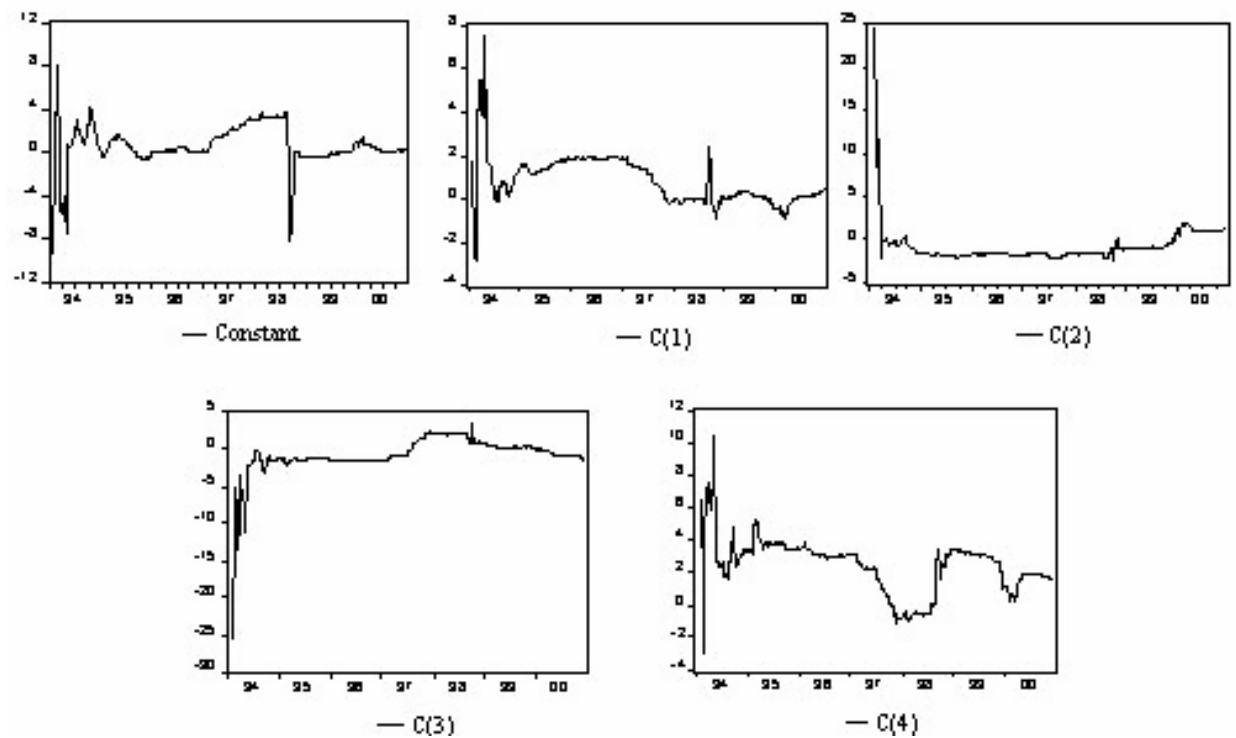

Figure 1. Temporal evolution of the five combination coefficients (constant included) relative to the 5-step-ahead forecasts for Italy 
Table 9. Rolling windows for forecast combination with variable weights

\begin{tabular}{lc}
\hline \hline \multicolumn{1}{c}{ Stock market } & Size of the rolling window \\
\hline Holland & 35 weekly observations \\
Belgium & 20 weekly observations \\
Germany & 15 weekly observations \\
U.K. & 25 weekly observations \\
Italy & 25 weekly observations \\
France & 35 weekly observations \\
Spain & 35 weekly observations \\
Portugal & 25 weekly observations \\
Switzerland & 20 weekly observations \\
Greece & 15 weekly observations \\
\hline \hline
\end{tabular}

Table 10a. Forecast combination with variable weights and Mincer-Zarnowitz regression

\begin{tabular}{|c|c|c|c|c|c|c|c|c|c|c|c|c|}
\hline \multicolumn{7}{|c|}{ Holland } & \multicolumn{6}{|c|}{ Belgium } \\
\hline Mod & $h$ MSPE & MedSPE & MAPE & MedAPE & $D M$ & $S$ & MSPE & MedSPE & $M A P E$ & MedAPE & $D M$ & $S$ \\
\hline \multirow[t]{6}{*}{ Comb } & 11.118 & 1.203 & 1.325 & 1.097 & 0.003 & 0.741 & 2.048 & 1.325 & 1.330 & 1.135 & 0.067 & 0.000 \\
\hline & 21.166 & 1.214 & 1.268 & 1.102 & 0.252 & 0.036 & 2.771 & 1.275 & 1.395 & 1.132 & 0.000 & 0.000 \\
\hline & 31.116 & 1.317 & 1.299 & 1.148 & 0.185 & 0.271 & 1.658 & 1.173 & 1.137 & 1.172 & 0.094 & 0.076 \\
\hline & $4 \quad 1.259$ & 1.118 & 1.151 & 1.057 & 0.474 & 0.078 & 0.949 & 0.921 & 1.182 & 1.149 & 0.053 & 0.046 \\
\hline & $\begin{array}{ll}5 & 1.287\end{array}$ & 1.470 & 1.320 & 1.213 & 0.298 & 0.099 & 0.990 & 0.853 & 0.920 & 1.005 & 0.138 & 0.419 \\
\hline & $h$ & 2 & 3 & 4 & 5 & & 1 & 2 & 3 & 4 & 5 & \\
\hline \multirow[t]{2}{*}{$\mathrm{a}$} & 2.474 & 2.415 & 2.392 & 2.383 & 2.530 & & 1.160 & 1.688 & 1.055 & 1.816 & 2.909 & \\
\hline & $(0.708)$ & $(0.707)$ & $(0.700)$ & $(0.759)$ & $(0.700)$ & & $(0.556)$ & $(0.511)$ & $(0.562)$ & $(0.580)$ & $(0.559)$ & \\
\hline \multirow[t]{2}{*}{ b } & 0.030 & 0.045 & 0.056 & 0.050 & 0.020 & & 0.014 & 0.262 & 0.006 & 0.041 & 0.036 & \\
\hline & $(0.043)$ & $(0.041)$ & $(0.038)$ & $(0.060)$ & $(0.036)$ & & $(0.011)$ & $(0.027)$ & $(0.017)$ & $(0.027)$ & $(0.021)$ & \\
\hline \multirow[t]{2}{*}{$R^{2}$} & 0.111 & 0.124 & 0.026 & 0.082 & 0.038 & & 0.095 & 0.212 & 0.033 & 0.097 & 0.129 & \\
\hline & \multicolumn{6}{|c|}{ Germany } & \multicolumn{6}{|c|}{ U.K. } \\
\hline \multirow[t]{6}{*}{ Comb } & 10.972 & 0.951 & 1.292 & 0.862 & 0.063 & 0.008 & 1.135 & 0.963 & 1.159 & 0.981 & 0.001 & 0.329 \\
\hline & 21.033 & 1.030 & 1.367 & 0.937 & 0.032 & 0.200 & 1.139 & 1.187 & 1.198 & 1.090 & 0.000 & 0.129 \\
\hline & 31.271 & 1.197 & 1.029 & 1.124 & 0.118 & 0.000 & 1.278 & 1.138 & 1.187 & 1.067 & 0.001 & 0.828 \\
\hline & 41.302 & 0.949 & 0.973 & 1.131 & 0.137 & 0.000 & 1.203 & 0.911 & 1.188 & 0.954 & 0.000 & 0.193 \\
\hline & $\begin{array}{ll}5 & 1.287\end{array}$ & 0.926 & 1.718 & 1.388 & 0.051 & 0.003 & 1.251 & 1.128 & 1.206 & 1.062 & 0.003 & 0.193 \\
\hline & $h$ & 2 & 3 & 4 & 5 & & 1 & 2 & 3 & 4 & 5 & \\
\hline \multirow[t]{2}{*}{$\mathrm{a}$} & 2.363 & 2.945 & 2.153 & 3.993 & 7.963 & & 2.561 & 2.966 & 1.894 & 1.455 & 1.864 & \\
\hline & $(0.889)$ & $(0.920)$ & $(0.898)$ & $(0.905)$ & $(0.934)$ & & $(0.471)$ & $(0.503)$ & $(0.522)$ & $(0.525)$ & $(0.503)$ & \\
\hline \multirow[t]{2}{*}{ b } & 0.011 & 0.090 & 0.005 & 0.016 & 0.027 & & 0.239 & 0.119 & 0.131 & 0.006 & 0.117 & \\
\hline & $(0.006)$ & $(0.033)$ & $(0.008)$ & $(0.011)$ & $(0.026)$ & & $(0.070)$ & $(0.074)$ & $(0.078)$ & $(0.080)$ & $(0.066)$ & \\
\hline$R^{2}$ & 0.110 & 0.061 & 0.021 & 0.137 & 0.043 & & 0.034 & 0.017 & 0.018 & 0.011 & 0.079 & \\
\hline
\end{tabular}

Notes to the table: see Table 8a. 
Table 10b. Forecast combination with variable weights and Mincer-Zarnowitz regression

\begin{tabular}{|c|c|c|c|c|c|c|c|c|c|c|c|c|}
\hline & & & Italy & & & & & & Fra & nce & & \\
\hline Mod & $h \mathbf{M S P E}$ & MedSPE & $M A P E$ & MedAPE & $D M$ & $S$ & MSPE & MedSPE & $M A P E$ & MedAPE & $D M$ & $S$ \\
\hline Comb & 11.263 & 1.184 & 1.353 & 1.088 & 0.002 & 0.002 & 1.103 & 1.295 & 1.209 & 1.138 & 0.000 & 0.036 \\
\hline & 21.176 & 1.337 & 1.108 & 1.156 & 0.006 & 0.000 & 1.212 & 1.194 & 1.183 & 1.093 & 0.000 & 0.047 \\
\hline & 31.232 & 1.037 & 1.003 & 1.019 & 0.007 & 0.013 & 0.992 & 1.154 & 1.184 & 1.074 & 0.027 & 0.077 \\
\hline & 41.295 & 1.120 & 0.898 & 1.058 & 0.000 & 0.129 & 1.289 & 0.900 & 1.167 & 1.140 & 0.000 & 0.020 \\
\hline & 51.001 & 0.946 & 0.914 & 0.973 & 0.003 & 0.278 & 1.128 & 1.108 & 1.141 & 1.052 & 0.014 & 0.098 \\
\hline & $h$ & 2 & 3 & 4 & 5 & & 1 & 2 & 3 & 4 & 5 & \\
\hline $\mathrm{a}$ & 1.503 & 1.434 & 1.969 & 1.406 & 1.617 & & 1.342 & 2.659 & 1.052 & 2.172 & 1.668 & \\
\hline & $(0.891)$ & $(0.911)$ & $(0.940)$ & (1.091) & (1.037) & & $(0.951)$ & (1.003) & $(0.839)$ & $(0.971)$ & $(0.983)$ & \\
\hline$b$ & 0.040 & 0.051 & 0.009 & 0.163 & 0.137 & & 0.151 & -0.056 & -0.009 & 0.118 & 0.269 & \\
\hline & $(0.040)$ & $(0.048)$ & $(0.049)$ & $(0.082)$ & $(0.073)$ & & $(0.082)$ & $(0.086)$ & $(0.062)$ & $(0.090)$ & $(0.079)$ & \\
\hline$R^{2}$ & 0.022 & 0.003 & 0.005 & 0.001 & 0.010 & & 0.019 & 0.024 & 0.016 & 0.015 & 0.035 & \\
\hline & & & Spain & & & & & & Port & ugal & & \\
\hline Comb & 11.259 & 1.078 & 1.008 & 1.038 & 0.010 & 0.091 & 1.357 & 1.351 & 1.195 & 1.162 & 0.005 & 0.223 \\
\hline & 21.109 & 0.801 & 1.040 & 0.895 & 0.035 & 0.736 & 1.429 & 1.048 & 1.220 & 1.024 & 0.199 & 0.268 \\
\hline & $\begin{array}{ll}3 & 0.921\end{array}$ & 1.088 & 0.924 & 1.043 & 0.054 & 0.144 & 1.591 & 1.123 & 1.150 & 1.060 & 0.079 & 0.506 \\
\hline & $\begin{array}{ll}4 & 0.917\end{array}$ & 1.123 & 0.937 & 1.106 & 0.030 & 0.368 & 1.938 & 1.087 & 1.201 & 1.043 & 0.026 & 0.438 \\
\hline & $\begin{array}{ll}5 & 1.507\end{array}$ & 1.195 & 1.136 & 1.138 & 0.135 & 0.500 & 1.824 & 1.007 & 1.326 & 1.003 & 0.265 & 0.376 \\
\hline & $h$ & 2 & 3 & 4 & 5 & & 1 & 2 & 3 & 4 & 5 & \\
\hline $\mathrm{a}$ & 2.304 & 2.962 & 2.108 & 2.110 & 3.116 & & 2.933 & 2.570 & 2.633 & 2.721 & 2.102 & \\
\hline & $(0.846)$ & $(0.893)$ & $(0.876)$ & $(0.989)$ & $(0.855)$ & & (1.016) & $(0.992)$ & (1.093) & $(1.052)$ & (1.039) & \\
\hline $\mathrm{b}$ & 0.095 & -0.034 & -0.012 & 0.081 & 0.045 & & 0.144 & 0.122 & 0.170 & 0.174 & 0.132 & \\
\hline & $(0.035)$ & $(0.055)$ & $(0.043)$ & $(0.087)$ & $(0.046)$ & & $(0.027)$ & $(0.020)$ & $(0.051)$ & $(0.041)$ & $(0.032)$ & \\
\hline$R^{2}$ & 0.022 & 0.017 & 0.020 & 0.026 & 0.009 & & 0.083 & 0.098 & 0.032 & 0.053 & 0.050 & \\
\hline & & & vitzerland & & & & & & Gre & ece & & \\
\hline Comb & 11.896 & 1.244 & 1.165 & 1.116 & 0.043 & 0.057 & 1.292 & 1.334 & 0.963 & 1.155 & 0.155 & 0.115 \\
\hline & 21.091 & 0.903 & 1.072 & 1.010 & 0.012 & 0.007 & 1.004 & 1.379 & 1.307 & 1.174 & 0.174 & 0.177 \\
\hline & 31.239 & 1.014 & 1.069 & 1.309 & 0.047 & 0.002 & 1.125 & 1.565 & 1.261 & 1.251 & 0.071 & 0.368 \\
\hline & 41.202 & 1.295 & 1.049 & 1.340 & 0.069 & 0.217 & 0.898 & 1.346 & 1.421 & 1.160 & 0.070 & 0.653 \\
\hline & 51.255 & 1.269 & 1.767 & 1.212 & 0.053 & 0.217 & 1.095 & 0.950 & 1.456 & 0.975 & 0.279 & 0.301 \\
\hline & $h$ & 2 & 3 & 4 & 5 & & 1 & 2 & 3 & 4 & 5 & \\
\hline $\mathrm{a}$ & 1.356 & 2.693 & 2.435 & 2.409 & 1.594 & & 4.811 & 4.980 & 4.919 & 4.130 & 4.021 & \\
\hline & $(0.928)$ & $(0.961)$ & $(0.948)$ & $(0.953)$ & $(0.944)$ & & $(1.796)$ & (1.803) & $(1.812)$ & (1.767) & (1.798) & \\
\hline $\mathrm{b}$ & 0.036 & 0.008 & 0.023 & 0.030 & 0.012 & & -0.002 & -0.001 & 0.000 & -0.025 & 0.000 & \\
\hline & $(0.018)$ & $(0.043)$ & $(0.024)$ & $(0.026)$ & $(0.024)$ & & $(0.004)$ & $(0.003)$ & $(0.009)$ & $(0.009)$ & $(0.001)$ & \\
\hline$R^{2}$ & 0.162 & 0.081 & 0.044 & 0.034 & 0.020 & & 0.001 & 0.001 & 0.000 & 0.022 & 0.001 & \\
\hline
\end{tabular}

Notes to the table: see Table 8 a. 


\title{
NOTE DI LAVORO DELLA FONDAZIONE ENI ENRICO MATTEI Fondazione Eni Enrico Mattei Working Papers Series \\ Our working papers are available on the Internet at the following addresses: Server $W W W$ : WWW.FEEM.IT \\ Anonymous FTP: FTP.FEEM.IT \\ http://papers.ssrn.com/abstract_id=XXXXXX
}

\begin{abstract}
SUST $\quad 1.2001 \quad$ Inge MAYERES and Stef PROOST: Should Diesel Cars in Europe be Discouraged?
SUST 2.2001 Paola DORIA and Davide PETTENELLA: The Decision Making Process in Defining and Protecting Critical Natural Capital

CLIM $3.2001 \quad$ Alberto PENCH: Green Tax Reforms in a Computable General Equilibrium Model for Italy

CLIM 4.2001 Maurizio BUSSOLO and Dino PINELLI: Green Taxes: Environment, Employment and Growth

CLIM 5.2001 Marco STAMPINI: Tax Reforms and Environmental Policies for Italy

ETA $\quad 6.2001$

CLIM $\quad 7.2001$

Walid OUESLATI: Environmental Fiscal Policy in an Endogenous Growth Model with Human Capital

Umberto CIORBA, Alessandro LANZA and Francesco PAULI: Kyoto Commitment and Emission Trading: a European Union Perspective

MGMT 8.2001 Brian SLACK (xlv): Globalisation in Maritime Transportation: Competition, uncertainty and implications for port development strategy

VOL 9.2001 Giulia PESARO: Environmental Voluntary Agreements: A New Model of Co-operation Between Public and Economic Actors

VOL $\quad 10.2001 \quad$ Cathrine HAGEM: Climate Policy, Asymmetric Information and Firm Survival

ETA 11.2001 Sergio CURRARINI and Marco MARINI: A Sequential Approach to the Characteristic Function and the Core in Games with Externalities

ETA 12.2001 Gaetano BLOISE, Sergio CURRARINI and Nicholas KIKIDIS: Inflation and Welfare in an OLG Economy with a Privately Provided Public Good

KNOW 13.2001 Paolo SURICO: Globalisation and Trade: A "New Economic Geography" Perspective

ETA $\quad 14.2001$ Valentina BOSETTI and Vincenzina MESSINA: Quasi Option Value and Irreversible Choices

CLIM $\quad 15.2001$

Guy ENGELEN (xlii): Desertification and Land Degradation in Mediterranean Areas: from Science to Integrated Policy Making

SUST $\quad 16.2001$ Julie Catherine SORS: Measuring Progress Towards Sustainable Development in Venice: A Comparative Assessment of Methods and Approaches

Julie Catherine SORS: Public Participation in Local Agenda 21: A Review of Traditional and Innovative Tools

CLIM $\quad 18.2001$

Johan ALBRECHT and Niko GOBBIN: Schumpeter and the Rise of Modern Environmentalism

VOL 19.2001 Rinaldo BRAU, Carlo CARRARO and Giulio GOLFETTO (xliii): Participation Incentives and the Design of Voluntary Agreements

ETA $20.2001 \quad$ Paola ROTA: Dynamic Labour Demand with Lumpy and Kinked Adjustment Costs

ETA $21.2001 \quad$ Paola ROTA: Empirical Representation of Firms' Employment Decisions by an (S,s) Rule

ETA 22.2001 Paola ROTA: What Do We Gain by Being Discrete? An Introduction to the Econometrics of Discrete Decision Processes

PRIV 23.2001 Stefano BOSI, Guillaume GIRMANS and Michel GUILLARD: Optimal Privatisation Design and Financial Markets

KNOW 24.2001 Giorgio BRUNELLO, Claudio LUPI, Patrizia ORDINE, and Maria Luisa PARISI: Beyond National Institutions: Labour Taxes and Regional Unemployment in Italy

ETA 25.2001 Klaus CONRAD: Locational Competition under Environmental Regulation when Input Prices and Productivity $\underline{\text { Differ }}$

PRIV $26.2001 \quad \overline{\text { Bernardo BORTOLOTTI, Juliet D'SOUZA, Marcella FANTINI and William L. MEGGINSON: Sources of }}$ Performance Improvement in Privatised Firms: A Clinical Study of the Global Telecommunications Industry

CLIM 27.2001 Frédéric BROCHIER and Emiliano RAMIERI: Climate Change Impacts on the Mediterranean Coastal Zones

ETA 28.2001 Nunzio CAPPUCCIO and Michele MORETTO: Comments on the Investment-Uncertainty Relationship in a Real Option Model

KNOW 29.2001 Giorgio BRUNELLO: Absolute Risk Aversion and the Returns to Education

CLIM 30.2001 ZhongXiang ZHANG: Meeting the Kyoto Targets: The Importance of Developing Country Participation

ETA 31.2001 Jonathan D. KAPLAN, Richard E. HOWITT and Y. Hossein FARZIN: An Information-Theoretical Analysis of Budget-Constrained Nonpoint Source Pollution Control

MGMT $32.2001 \quad$ Roberta SALOMONE and Giulia GALLUCCIO: Environmental Issues and Financial Reporting Trends

Coalition

Theory

ETA $\quad 34.200$

33.2001 Shlomo WEBER and Hans WIESMETH: From Autarky to Free Trade: The Impact on Environment

34.2001 Margarita GENIUS and Elisabetta STRAZZERA: Model Selection and Tests for Non Nested Contingent Valuation Models: An Assessment of Methods
\end{abstract}


NRM 35.2001 Carlo GIUPPONI: The Substitution of Hazardous Molecules in Production Processes: The Atrazine Case Study in Italian Agriculture

KNOW 36.2001 Raffaele PACI and Francesco PIGLIARU: Technological Diffusion, Spatial Spillovers and Regional Convergence in Europe

PRIV 37.2001 Bernardo BORTOLOTTI: Privatisation, Large Shareholders, and Sequential Auctions of Shares

CLIM 38.2001 Barbara BUCHNER: What Really Happened in The Hague? Report on the COP6, Part I, 13-25 November 2000, The Hague, The Netherlands

PRIV 39.2001 Giacomo CALZOLARI and Carlo SCARPA: Regulation at Home, Competition Abroad: A Theoretical Framework

KNOW $40.2001 \quad$ Giorgio BRUNELLO: On the Complementarity between Education and Training in Europe

Coalition 41.2001 Alain DESDOIGTS and Fabien MOIZEAU (xlvi): Multiple Politico-Economic Regimes, Inequality and Growth

Theory

Network

Coalition

42.2001

Parkash CHANDER and Henry TULKENS (xlvi): Limits to Climate Change

Coalition

Theory

Network

Coalition

Theory

Network

NRM

43.2001

Michael FINUS and Bianca RUNDSHAGEN (xlvi): Endogenous Coalition Formation in Global Pollution $\underline{\text { Control }}$

44.2001 Wietze LISE, Richard S.J. TOL and Bob van der ZWAAN (xlvi): Negotiating Climate Change as a Social $\underline{\text { Situation }}$

45.2001 Mohamad R. KHAWLIE (xlvii): The Impacts of Climate Change on Water Resources of Lebanon- Eastern Mediterranean

NRM 46.2001 Mutasem EL-FADEL and E. BOU-ZEID (xlvii): Climate Change and Water Resources in the Middle East: Vulnerability, Socio-Economic Impacts and Adaptation

NRM 47.2001 Eva IGLESIAS, Alberto GARRIDO and Almudena GOMEZ (xlvii): An Economic Drought Management Index to Evaluate Water Institutions' Performance Under Uncertainty and Climate Change

CLIM $\quad 48.2001 \quad$ Wietze LISE and Richard S.J. TOL (xlvii): Impact of Climate on Tourist Demand

CLIM 49.2001 Francesco BOSELLO, Barbara BUCHNER, Carlo CARRARO and Davide RAGGI: Can Equity Enhance Efficiency? Lessons from the Kyoto Protocol

SUST $\quad 50.2001 \quad$ Roberto ROSON (xlviii): Carbon Leakage in a Small Open Economy with Capital Mobility

SUST 51.2001 Edwin WOERDMAN (xlviii): Developing a European Carbon Trading Market: Will Permit Allocation Distort Competition and Lead to State Aid?

SUST $52.2001 \quad$ Richard N. COOPER (xlviii): The Kyoto Protocol: A Flawed Concept

SUST

SUST

53.2001 Kari KANGAS (xlviii): Trade Liberalisation, Changing Forest Management and Roundwood Trade in Europe

54.2001 Xueqin ZHU and Ekko VAN IERLAND (xlviii): Effects of the Enlargement of EU on Trade and the Environment

SUST 55.2001 M. Ozgur KAYALICA and Sajal LAHIRI (xlviii): Strategic Environmental Policies in the Presence of Foreign Direct Investment

SUST 56.2001 Savas ALPAY (xlviii): Can Environmental Regulations be Compatible with Higher International Competitiveness? Some New Theoretical Insights

SUST 57.2001 Roldan MURADIAN, Martin O'CONNOR, Joan MARTINEZ-ALER (xlviii): Embodied Pollution in Trade: Estimating the "Environmental Load Displacement" of Industrialised Countries

SUST 58.2001 Matthew R. AUER and Rafael REUVENY (xlviii): Foreign Aid and Direct Investment: Key Players in the Environmental Restoration of Central and Eastern Europe

SUST 59.2001 Onno J. KUIK and Frans H. OOSTERHUIS (xlviii): Lessons from the Southern Enlargement of the EU for the Environmental Dimensions of Eastern Enlargement, in particular for Poland

ETA 60.2001 Carlo CARRARO, Alessandra POME and Domenico SINISCALCO (xlix): Science vs. Profit in Research: Lessons from the Human Genome Project

CLIM 61.2001 Efrem CASTELNUOVO, Michele MORETTO and Sergio VERGALLI: Global Warming, Uncertainty and Endogenous Technical Change: Implications for Kyoto

PRIV 62.2001 Gian Luigi ALBANO, Fabrizio GERMANO and Stefano LOVO: On Some Collusive and Signaling Equilibria in Ascending Auctions for Multiple Objects

CLIM 63.2001 Elbert DIJKGRAAF and Herman R.J. VOLLEBERGH: $\underline{\text { A Note on Testing for Environmental Kuznets Curves }}$ with Panel Data

CLIM 64.2001 Paolo BUONANNO, Carlo CARRARO and Marzio GALEOTTI: Endogenous Induced Technical Change and the Costs of Kyoto

CLIM 65.2001 Guido CAZZAVILLAN and Ignazio MUSU (1): Transitional Dynamics and Uniqueness of the Balanced-Growth Path in a Simple Model of Endogenous Growth with an Environmental Asset

CLIM 66.2001 Giovanni BAIOCCHI and Salvatore DI FALCO (1): Investigating the Shape of the EKC: A Nonparametric Approach

CLIM 67.2001 Marzio GALEOTTI, Alessandro LANZA and Francesco PAULI (1): Desperately Seeking (Environmental) Kuznets: A New Look at the Evidence

CLIM 68.2001 Alexey VIKHLYAEV (xlviii): The Use of Trade Measures for Environmental Purposes - Globally and in the EU Context

NRM 69.2001 Gary D. LIBECAP and Zeynep K. HANSEN (li): $\underline{\text { U.S. Land Policy, Property Rights, and the Dust Bowl of the }}$ $\underline{1930 \mathrm{~s}}$ 
Lee J. ALSTON, Gary D. LIBECAP and Bernardo MUELLER (li): Land Reform Policies, The Sources of Violent Conflict and Implications for Deforestation in the Brazilian Amazon

CLIM $71.2001 \quad$ Claudia KEMFERT: Economy-Energy-Climate Interaction - The Model WIAGEM -

SUST 72.2001 Paulo A.L.D. NUNES and Yohanes E. RIYANTO: Policy Instruments for Creating Markets for Bodiversity: Certification and Ecolabeling

SUST $\quad 73.2001 \quad$ Paulo A.L.D. NUNES and Erik SCHOKKAERT (lii): Warm Glow and Embedding in Contingent Valuation

SUST 74.2001 Paulo A.L.D. NUNES, Jeroen C.J.M. van den BERGH and Peter NIJKAMP (lii): Ecological-Economic Analysis and Valuation of Biodiversity

VOL 75.2001 Johan EYCKMANS and Henry TULKENS (li): Simulating Coalitionally Stable Burden Sharing Agreements for the Climate Change Problem

PRIV 76.2001 Axel GAUTIER and Florian HEIDER: What Do Internal Capital Markets Do? Redistribution vs. Incentives

PRIV 77.2001 Bernardo BORTOLOTTI, Marcella FANTINI and Domenico SINISCALCO: Privatisation around the World: New Evidence from Panel Data

ETA $78.2001 \quad$ Toke S. AIDT and Jayasri DUTTA (li): Transitional Politics. Emerging Incentive-based Instruments in Environmental Regulation

ETA 79.2001 Alberto PETRUCCI: Consumption Taxation and Endogenous Growth in a Model with New Generations

ETA 80.2001 Pierre LASSERRE and Antoine SOUBEYRAN (li): A Ricardian Model of the Tragedy of the Commons

ETA 81.2001 Pierre COURTOIS, Jean Christophe PÉREAU and Tarik TAZDAÏT: An Evolutionary Approach to the Climate Change Negotiation Game

NRM 82.2001 Christophe BONTEMPS, Stéphane COUTURE and Pascal FAVARD: Is the Irrigation Water Demand Really Convex?

NRM 83.2001 Unai PASCUAL and Edward BARBIER: A Model of Optimal Labour and Soil Use with Shifting Cultivation

CLIM 84.2001 Jesper JENSEN and Martin Hvidt THELLE: What are the Gains from a Multi-Gas Strategy?

CLIM 85.2001 Maurizio MICHELINI (liii): IPCC "Summary for Policymakers" in TAR. Do its results give a scientific support always adequate to the urgencies of Kyoto negotiations?

CLIM

CLIM

86.2001 Claudia KEMFERT (liii): Economic Impact Assessment of Alternative Climate Policy Strategies

ETA $\quad 88.2001$ Cesare DOSI and Michele MORETTO: Global Warming and Financial Umbrellas

ETA $\quad 89.200$ Elena BONTEMPI, Alessandra DEL BOCA, Alessandra FRANZOSI, Marzio GALEOTTI and Paola ROTA: Capital Heterogeneity: Does it Matter? Fundamental $Q$ and Investment on a Panel of Italian Firms Efrem CASTELNUOVO and Paolo SURICO: $\underline{\text { Model Uncertainty, Optimal Monetary Policy and the Preferences }}$ of the Fed

CLIM 90.2001 Umberto CIORBA, Alessandro LANZA and Francesco PAULI: Kyoto Protocol and Emission Trading: Does the US Make a Difference?

CLIM 91.2001 ZhongXiang ZHANG and Lucas ASSUNCAO: Domestic Climate Policies and the WTO

SUST 92.2001 Anna ALBERINI, Alan KRUPNICK, Maureen CROPPER, Nathalie SIMON and Joseph COOK (lii): The Willingness to Pay for Mortality Risk Reductions: A Comparison of the United States and Canada

SUST 93.2001 Riccardo SCARPA, Guy D. GARROD and Kenneth G. WILLIS (lii): Valuing Local Public Goods with Advanced Stated Preference Models: Traffic Calming Schemes in Northern England

CLIM 94.2001 Ming CHEN and Larry KARP: Environmental Indices for the Chinese Grain Sector

CLIM 95.2001 Larry KARP and Jiangfeng ZHANG: Controlling a Stock Pollutant with Endogenous Investment and Asymmetric Information

ETA $96.2001 \quad$ Michele MORETTO and Gianpaolo ROSSINI: On the Opportunity Cost of Nontradable Stock Options

SUST 97.2001 Elisabetta STRAZZERA, Margarita GENIUS, Riccardo SCARPA and George HUTCHINSON: The Effect of Protest Votes on the Estimates of Willingness to Pay for Use Values of Recreational Sites

NRM 98.2001 Frédéric BROCHIER, Carlo GIUPPONI and Alberto LONGO: Integrated Coastal Zone Management in the Venice Area - Perspectives of Development for the Rural Island of Sant'Erasmo

NRM 99.2001 Frédéric BROCHIER, Carlo GIUPPONI and Julie SORS: Integrated Coastal Management in the Venice AreaPotentials of the Integrated Participatory Management Approach

NRM 100.2001 Frédéric BROCHIER and Carlo GIUPPONI: Integrated Coastal Zone Management in the Venice Area - A Methodological Framework

PRIV 101.2001 Enrico C. PEROTTI and Luc LAEVEN: Confidence Building in Emerging Stock Markets

CLIM 102.2001 Barbara BUCHNER, Carlo CARRARO and Igor CERSOSIMO: On the Consequences of the U.S. Withdrawal from the Kyoto/Bonn Protocol

SUST 103.2001 Riccardo SCARPA, Adam DRUCKER, Simon ANDERSON, Nancy FERRAES-EHUAN, Veronica GOMEZ, Carlos R. RISOPATRON and Olga RUBIO-LEONEL: Valuing Animal Genetic Resources in Peasant Economies: The Case of the Box Keken Creole Pig in Yucatan

SUST 104.2001 R. SCARPA, P. KRISTJANSON, A. DRUCKER, M. RADENY, E.S.K. RUTO, and J.E.O. REGE: Valuing Indigenous Cattle Breeds in Kenya: An Empirical Comparison of Stated and Revealed Preference Value Estimates

SUST 105.2001 Clemens B.A. WOLLNY: The Need to Conserve Farm Animal Genetic Resources Through Community-Based Management in Africa: Should Policy Makers be Concerned?

SUST $\quad 106.2001$ J.T. KARUGIA, O.A. MWAI, R. KAITHO, Adam G. DRUCKER, C.B.A. WOLLNY and J.E.O. REGE: Economic Analysis of Crossbreeding Programmes in Sub-Saharan Africa: A Conceptual Framework and Kenyan Case $\underline{\text { Study }}$

SUST 107.2001 W. AYALEW, J.M. KING, E. BRUNS and B. RISCHKOWSKY: Economic Evaluation of Smallholder Subsistence Livestock Production: Lessons from an Ethiopian Goat Development Program 
108.2001 Gianni CICIA, Elisabetta D'ERCOLE and Davide MARINO: Valuing Farm Animal Genetic Resources by Means of Contingent Valuation and a Bio-Economic Model: The Case of the Pentro Horse

SUST

109.2001 Clem TISDELL: Socioeconomic Causes of Loss of Animal Genetic Diversity: Analysis and Assessment

SUST 110.2001 M.A. JABBAR and M.L. DIEDHOU: Does Breed Matter to Cattle Farmers and Buyers? Evidence from West $\underline{\text { Africa }}$

SUST $\quad 1.2002 \quad$ K. TANO, M.D. FAMINOW, M. KAMUANGA and B. SWALLOW: Using Conjoint Analysis to Estimate Farmers' Preferences for Cattle Traits in West Africa

ETA 2.2002 Efrem CASTELNUOVO and Paolo SURICO: What Does Monetary Policy Reveal about Central Bank's Preferences?

WAT 3.2002 Duncan KNOWLER and Edward BARBIER: The Economics of a "Mixed Blessing" Effect: A Case Study of the Black Sea

CLIM $\quad 4.2002$

VOL $\quad 5.2002$

CLIM 6.2002

Andreas LÖSCHEL: Technological Change in Economic Models of Environmental Policy: A Survey

Carlo CARRARO and Carmen MARCHIORI: Stable Coalitions

ETA $7.2002 \quad \begin{aligned} & \text { Comparison on European Gasoline Markets } \\ & \text { Effrosyni DIAMANTOUDI and Eftichios S. SARTZETAKIS: Stable International Environmental Agreements: An } \\ & \text { Analytical Approach }\end{aligned}$

KNOW 8.2002 Alain DESDOIGTS: Neoclassical Convergence Versus Technological Catch-up: A Contribution for Reaching a Consensus

NRM $\quad 9.2002 \quad$ Giuseppe DI VITA: Renewable Resources and Waste Recycling

KNOW 10.2002 Giorgio BRUNELLO: Is Training More Frequent when Wage Compression is Higher? Evidence from 11 European Countries

ETA 11.2002 Mordecai KURZ, Hehui JIN and Maurizio MOTOLESE: Endogenous Fluctuations and the Role of Monetary Policy

KNOW 12.2002 Reyer GERLAGH and Marjan W. HOFKES: Escaping Lock-in: The Scope for a Transition towards Sustainable Growth?

NRM 13.2002 Michele MORETTO and Paolo ROSATO: The Use of Common Property Resources: A Dynamic Model

CLIM 14.2002 Philippe QUIRION: Macroeconomic Effects of an Energy Saving Policy in the Public Sector

CLIM 15.2002 Roberto ROSON: Dynamic and Distributional Effects of Environmental Revenue Recycling Schemes: Simulations with a General Equilibrium Model of the Italian Economy

CLIM $16.2002 \quad$ Francesco RICCI (1): Environmental Policy Growth when Inputs are Differentiated in Pollution Intensity

ETA 17.2002 Alberto PETRUCCI: Devaluation (Levels versus Rates) and Balance of Payments in a Cash-in-Advance Economy

Coalition $\quad 18.200$

László Á. KÓCZY (liv): The Core in the Presence of Externalities

Theory

Network

Coalition 19.2002

Theory

Network

Coalition

Theory

Network

NRM

Steven J. BRAMS, Michael A. JONES and D. Marc KILGOUR (liv): Single-Peakedness and Disconnected Coalitions

20.2002

Guillaume HAERINGER (liv): On the Stability of Cooperation Structures

CLIM 22.2002

Fausto CAVALLARO and Luigi CIRAOLO: Economic and Environmental Sustainability: A Dynamic Approach in Insular Systems

CLIM 23.2002

Barbara BUCHNER, Carlo CARRARO, Igor CERSOSIMO and Carmen MARCHIORI: Back to Kyoto? US Participation and the Linkage between R\&D and Climate Cooperation

ETA 24.2002

Andreas LÖSCHEL and ZhongXIANG ZHANG: The Economic and Environmental Implications of the US Repudiation of the Kyoto Protocol and the Subsequent Deals in Bonn and Marrakech

CLIM 25.2002

Marzio GALEOTTI, Louis J. MACCINI and Fabio SCHIANTARELLI: Inventories, Employment and Hours

ETA 26.200

Hannes EGLI: Are Cross-Country Studies of the Environmental Kuznets Curve Misleading? New Evidence from Time Series Data for Germany

\section{SUST $\quad 27.2002$}

SUST 28.2002

Joseph C. COOPER and Giovanni SIGNORELLO: Farmer Premiums for the Voluntary Adoption of Conservation Plans

KNOW 29.2002

The ANSEA Network: Towards An Analytical Strategic Environmental Assessment

ETA $\quad 30.2002$

NRM $\quad 31.2002$

Geographic Concentration and Increasing Returns. a Survey of Evidence

Robert N. STAVINS: Lessons from the American Experiment with Market-Based Environmental Policies

NRM $\quad 32.2002$

the Catchment Scale: An Application to Diffuse Pollution Control in the Venice Lagoon

Robert N. STAVINS: National Environmental Policy During the Clinton Years

KNOW $\quad 33.2002$

A. SOUBEYRAN and H. STAHN : Do Investments in Specialized Knowledge Lead to Composite Good Industries?

KNOW $34.2002 \quad \overline{\text { G. BRUNELLO, M.L. PARISI and Daniela SONEDDA: Labor Taxes, Wage Setting and the Relative Wage }}$ $\underline{\text { Effect }}$

CLIM $35.2002 \quad$ C. BOEMARE and P. QUIRION (lv): Implementing Greenhouse Gas Trading in Europe: Lessons from Economic Theory and International Experiences 
CLIM

CLIM

CLIM

SUST

NRM

NRM

CLIM

CLIM

CLIM

ETA

ETA

SUST

SUST

KNOW

Coalition

Theory

Network

Coalition

Theory

Network

ETA

ETA

CLIM

ETA

SUST

SUST

SUST

SUST

VOL

ETA

PRIV

PRIV

PRIV

SUST

ETA

PRIV

CLIM

CLIM

SUST

SUST

NRM

PRIV

PRIV

PRIV

PRIV
36.2002

37.2002

38.2002

39.2002

40.2002

41.2002

42.2002

43.2002

44.2002

45.2002

46.2002

47.2002

48.2002

49.2002

50.2002

51.2002

52.2002

53.2002

54.2002

55.2002

56.2002

57.2002

58.2002

59.2002

60.2002

62.2002

63.2002

64.2002

65.2002

66.2002

67.2002

68.2002

69.2002

70.2002

71.2002

72.2002

73.2002

74.2002

75.2002

76.2002

T.TIETENBERG (lv): The Tradable Permits Approach to Protecting the Commons: What Have We Learned? K. REHDANZ and R.J.S. TOL (lv): On National and International Trade in Greenhouse Gas Emission Permits C. FISCHER (lv): Multinational Taxation and International Emissions Trading

G. SIGNORELLO and G. PAPPALARDO: Farm Animal Biodiversity Conservation Activities in Europe under the Framework of Agenda 2000

S.M. CAVANAGH, W. M. HANEMANN and R. N. STAVINS: Muffled Price Signals: Household Water Demand under Increasing-Block Prices

A. J. PLANTINGA, R. N. LUBOWSKI and R. N. STAVINS: The Effects of Potential Land Development on Agricultural Land Prices

C. OHL (lvi): Inducing Environmental Co-operation by the Design of Emission Permits

J. EYCKMANS, D. VAN REGEMORTER and V. VAN STEENBERGHE (lvi): Is Kyoto Fatally Flawed? An Analysis with MacGEM

A. ANTOCI and S. BORGHESI (lvi): Working Too Much in a Polluted World: A North-South Evolutionary Model

P. G. FREDRIKSSON, Johan A. LIST and Daniel MILLIMET (lvi): $\underline{\text { Chasing the Smokestack: Strategic }}$

Policymaking with Multiple Instruments

Z. YU (lvi): A Theory of Strategic Vertical DFI and the Missing Pollution-Haven Effect

Y. H. FARZIN: Can an Exhaustible Resource Economy Be Sustainable?

Y. H. FARZIN: Sustainability and Hamiltonian Value

C. PIGA and M. VIVARELLI: Cooperation in R\&D and Sample Selection

M. SERTEL and A. SLINKO (liv): Ranking Committees, Words or Multisets

Sergio CURRARINI (liv): $\underline{\text { Stable Organizations with Externalities }}$

Robert N. STAVINS: Experience with Market-Based Policy Instruments

C.C. JAEGER, M. LEIMBACH, C. CARRARO, K. HASSELMANN, J.C. HOURCADE, A. KEELER and

R. KLEIN (liii): Integrated Assessment Modeling: Modules for Cooperation

Scott BARRETT (liii): Towards a Better Climate Treaty

Richard G. NEWELL and Robert N. STAVINS: Cost Heterogeneity and the Potential Savings from MarketBased Policies

Paolo ROSATO and Edi DEFRANCESCO: Individual Travel Cost Method and Flow Fixed Costs

Vladimir KOTOV and Elena NIKITINA (lvii): Reorganisation of Environmental Policy in Russia: The Decade of Success and Failures in Implementation of Perspective Quests

Vladimir KOTOV (lvii): Policy in Transition: New Framework for Russia's Climate Policy

Fanny MISSFELDT and Arturo VILLAVICENCO (lvii): Trading or Joint Implementation?

Giovanni DI BARTOLOMEO, Jacob ENGWERDA, Joseph PLASMANS and Bas VAN AARLE: $\underline{\text { Staying Together }}$ or Breaking Apart: Policy-Makers' Endogenous Coalitions Formation in the European Economic and Monetary Union

Terms: Dynamic Efficiency Plus Intergenerational Equity

Carlo CAPUANO: Demand Growth, Entry and Collusion Sustainability

Federico MUNARI and Raffaele ORIANI: Privatization and R\&D Performance: An Empirical Analysis Based on Tobin's Q

Federico MUNARI and Maurizio SOBRERO: The Effects of Privatization on R\&D Investments and Patent Productivity

Orley ASHENFELTER and Michael GREENSTONE: Using Mandated Speed Limits to Measure the Value of a Statistical Life

Paolo SURICO: US Monetary Policy Rules: the Case for Asymmetric Preferences

Rinaldo BRAU and Massimo FLORIO: Privatisations as Price Reforms: Evaluating Consumers' Welfare Changes in the U.K.

Barbara K. BUCHNER and Roberto ROSON: Conflicting Perspectives in Trade and Environmental Negotiations Philippe QUIRION: Complying with the Kyoto Protocol under Uncertainty: Taxes or Tradable Permits?

Anna ALBERINI, Patrizia RIGANTI and Alberto LONGO: Can People Value the Aesthetic and Use Services of Urban Sites? Evidence from a Survey of Belfast Residents

Marco PERCOCO: Discounting Environmental Effects in Project Appraisal

Philippe BONTEMS and Pascal FAVARD: Input Use and Capacity Constraint under Uncertainty: The Case of Irrigation

Mohammed OMRAN: The Performance of State-Owned Enterprises and Newly Privatized Firms: Empirical Evidence from Egypt

Mike BURKART, Fausto PANUNZI and Andrei SHLEIFER: Family Firms

Emmanuelle AURIOL, Pierre M. PICARD: Privatizations in Developing Countries and the Government Budget Constraint

Nichole M. CASTATER: Privatization as a Means to Societal Transformation: An Empirical Study of Privatization in Central and Eastern Europe and the Former Soviet Union 


\begin{tabular}{|c|c|c|}
\hline PRIV & 02 & of Privatization \\
\hline PRIV & 78.2002 & $\begin{array}{l}\text { Kate BISHOP, Igor FILATOTCHEV and Tomasz MICKIEWICZ: Endogenous Ownership Structure: Factors } \\
\text { Affecting the Post-Privatisation Equity in Largest Hungarian Firms }\end{array}$ \\
\hline PRIV & 79.2002 & $\begin{array}{l}\text { Theodora WELCH and Rick MOLZ: How Does Trade Sale Privatization Work? } \\
\text { Evidence from the Fixed-Line Telecommunications Sector in Developing Economies }\end{array}$ \\
\hline PRIV & 80.2002 & $\begin{array}{l}\text { Alberto R. PETRUCCI: Government Debt, Agent Heterogeneity and Wealth Displacement in a Small Open } \\
\text { Economy }\end{array}$ \\
\hline CLIM & 81.2002 & $\begin{array}{l}\text { Timothy SWANSON and Robin MASON (lvi): The Impact of International Environmental Agreements: The Case } \\
\text { of the Montreal Protocol }\end{array}$ \\
\hline PRIV & 82.2002 & $\begin{array}{l}\text { George R.G. CLARKE and Lixin Colin XU: Privatization, Competition and Corruption: How Characteristics of } \\
\text { Bribe Takers and Payers Affect Bribe Payments to Utilities }\end{array}$ \\
\hline PRIV & 83.2002 & $\begin{array}{l}\text { Massimo FLORIO and Katiuscia MANZONI: The Abnormal Returns of UK Privatisations: From Underpricing } \\
\text { to Outperformance }\end{array}$ \\
\hline NRM & 84.2002 & $\begin{array}{l}\text { Nelson LOURENÇO, Carlos RUSSO MACHADO, Maria do ROSÁRIO JORGE and Luis RODRIGUES: An } \\
\text { Integrated Approach to Understand Territory Dynamics. The Coastal Alentejo (Portugal) }\end{array}$ \\
\hline CLIM & 85.2002 & $\begin{array}{l}\text { Peter ZAPFEL and Matti VAINIO (lv): Pathways to European Greenhouse Gas Emissions Trading History and } \\
\text { Misconceptions }\end{array}$ \\
\hline CLIM & 86.2002 & Pierre COURTOIS: Influence Processes in Climate Change Negotiations: Modelling the Rounds \\
\hline ETA & 87.2002 & Vito FRA GNELLI and Maria Erminia MARINA (lviii): Environmental Pollution Risk and Insurance \\
\hline ETA & 88.2002 & Laurent FRANCKX (lviii): Environmental Enforcement with Endogenous Ambient Monitoring \\
\hline ETA & 89.2002 & $\begin{array}{l}\text { Timo GOESCHL and Timothy M. SWANSON (lviii): Lost Horizons. The noncooperative management of an } \\
\text { evolutionary biological system. }\end{array}$ \\
\hline ETA & 90.2002 & Hans KEIDING (lviii): Environmental Effects of Consumption: An Approach Using DEA and Cost Sharing \\
\hline ETA & 91.2002 & Wietze LISE (lviii): A Game Model of People's Participation in Forest Management in Northern India \\
\hline CLIM & 92.2002 & Jens HORBACH: Structural Change and Environmental Kuznets Curves \\
\hline ETA & 93.2002 & $\begin{array}{l}\text { Martin P. GROSSKOPF: Towards a More Appropriate Method for Determining the Optimal Scale of Production } \\
\text { Units }\end{array}$ \\
\hline VOL & 94.2002 & 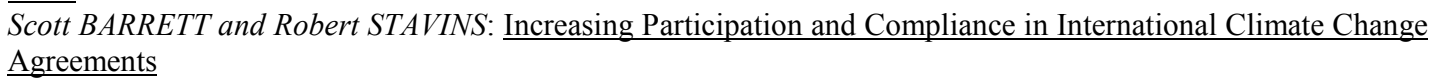 \\
\hline CLIM & 95.2002 & $\begin{array}{l}\text { Banu BAYRAMOGLU LISE and Wietze LISE: Climate Change, Environmental NGOs and Public Awareness in } \\
\text { the Netherlands: Perceptions and Reality }\end{array}$ \\
\hline CLIM & 96.2002 & Matthieu GLACHANT: The Political Economy of Emission Tax Design in Environmental Policy \\
\hline KNOW & 97.2002 & $\begin{array}{l}\text { Kenn ARIGA and Giorgio BRUNELLO: Are the More Educated Receiving More Training? Evidence from } \\
\text { Thailand }\end{array}$ \\
\hline ETA & 98.2002 & $\begin{array}{l}\text { Gianfranco FORTE and Matteo MANERA: Forecasting Volatility in European Stock Markets with Non-linear } \\
\text { GARCH Models }\end{array}$ \\
\hline
\end{tabular}

(xlii) This paper was presented at the International Workshop on "Climate Change and Mediterranean Coastal Systems: Regional Scenarios and Vulnerability Assessment" organised by the Fondazione Eni Enrico Mattei in co-operation with the Istituto Veneto di Scienze, Lettere ed Arti, Venice, December 9-10, 1999.

(xliii)This paper was presented at the International Workshop on "Voluntary Approaches, Competition and Competitiveness" organised by the Fondazione Eni Enrico Mattei within the research activities of the CAVA Network, Milan, May 25-26,2000.

(xliv) This paper was presented at the International Workshop on "Green National Accounting in Europe: Comparison of Methods and Experiences" organised by the Fondazione Eni Enrico Mattei within the Concerted Action of Environmental Valuation in Europe (EVE), Milan, March 4-7, 2000 (xlv) This paper was presented at the International Workshop on "New Ports and Urban and Regional Development. The Dynamics of Sustainability" organised by the Fondazione Eni Enrico Mattei, Venice, May 5-6, 2000.

(xlvi) This paper was presented at the Sixth Meeting of the Coalition Theory Network organised by the Fondazione Eni Enrico Mattei and the CORE, Université Catholique de Louvain, Louvain-laNeuve, Belgium, January 26-27, 2001

(xlvii) This paper was presented at the RICAMARE Workshop "Socioeconomic Assessments of Climate Change in the Mediterranean: Impact, Adaptation and Mitigation Co-benefits", organised by the Fondazione Eni Enrico Mattei, Milan, February 9-10, 2001

(xlviii) This paper was presented at the International Workshop "Trade and the Environment in the Perspective of the EU Enlargement ", organised by the Fondazione Eni Enrico Mattei, Milan, May $17-18,2001$

(xlix) This paper was presented at the International Conference "Knowledge as an Economic Good", organised by Fondazione Eni Enrico Mattei and The Beijer International Institute of Environmental Economics, Palermo, April 20-21, 2001

(1) This paper was presented at the Workshop "Growth, Environmental Policies and Sustainability” organised by the Fondazione Eni Enrico Mattei, Venice, June 1, 2001 
(li) This paper was presented at the Fourth Toulouse Conference on Environment and Resource Economics on "Property Rights, Institutions and Management of Environmental and Natural Resources", organised by Fondazione Eni Enrico Mattei, IDEI and INRA and sponsored by MATE, Toulouse, May 3-4, 2001

(lii) This paper was presented at the International Conference on "Economic Valuation of Environmental Goods", organised by Fondazione Eni Enrico Mattei in cooperation with CORILA, Venice, May 11, 2001

(liii) This paper was circulated at the International Conference on "Climate Policy - Do We Need a New Approach?", jointly organised by Fondazione Eni Enrico Mattei, Stanford University and Venice International University, Isola di San Servolo, Venice, September 6-8, 2001

(liv) This paper was presented at the Seventh Meeting of the Coalition Theory Network organised by the Fondazione Eni Enrico Mattei and the CORE, Université Catholique de Louvain, Venice, Italy, January 11-12, 2002

(lv) This paper was presented at the First Workshop of the Concerted Action on Tradable Emission Permits (CATEP) organised by the Fondazione Eni Enrico Mattei, Venice, Italy, December 3-4, 2001 (lvi) This paper was presented at the ESF EURESCO Conference on Environmental Policy in a Global Economy "The International Dimension of Environmental Policy", organised with the collaboration of the Fondazione Eni Enrico Mattei , Acquafredda di Maratea, October 6-11, 2001

(lvii) This paper was presented at the First Workshop of "CFEWE - Carbon Flows between Eastern and Western Europe", organised by the Fondazione Eni Enrico Mattei and Zentrum fur Europaische Integrationsforschung (ZEI), Milan, July 5-6, 2001

(lviii) This paper was presented at the Workshop on "Game Practice and the Environment", jointly organised by Università del Piemonte Orientale and Fondazione Eni Enrico Mattei, Alessandria, April 12-13, 2002

\section{SERIES}

CLIM Climate Change Modelling and Policy (Editor: Marzio Galeotti )

VOL Voluntary and International Agreements (Editor: Carlo Carraro)

SUST Sustainability Indicators and Environmental Evaluation (Editor: Carlo Carraro)

NRM Natural Resources Management (Editor: Carlo Giupponi)

KNOW Knowledge, Technology, Human Capital (Editor: Dino Pinelli)

MGMT Corporate Sustainable Management (Editor: Andrea Marsanich)

PRIV Privatisation, Regulation, Antitrust (Editor: Bernardo Bortolotti)

ETA Economic Theory and Applications (Editor: Carlo Carraro) 